\title{
PRENSA COSTARRICENSE Y HECHOS DESTACADOS DE LA SEGUNDA GUERRA MUNDIAL (1939-1945)
}

\author{
COSTA RICAN PRESS AND HIGHLIGHTS OF \\ THE SECOND WORLD WAR (1939-1945)
}

Patricia Vega Jiménez

Recibido: 06/05/2019 - Aceptado: 25/08/2019

\begin{abstract}
Resumen
El objetivo de este texto es analizar la forma en que el Diario de Costa Rica trató los principales hechos de la Segunda Guerra Mundial entre 1939 y 1945. Se seleccionaron los 14 momentos fundamentales: la invasión a Polonia, la declaratoria de guerra de Francia e Inglaterra, las invasiones alemanas al Norte y este de Europa, la caída de París ante los germanos, el armisticio y ocupación de Francia, la invasión a Rusia, el ataque a Pearl Harbor, el desembarco y batalla de Normandía, la liberación de París, la muerte de Mussolini, la capitulación de Alemania y el bombardeo atómico a Hiroshima y Nagasaki. Metodológicamente se procedió informándose sobre estos hechos en estudios académicos de alto nivel y se contrastó con lo señalado por el periódico. El resultado es una evidente tergiversación de las informaciones que además llegaban sesgadas por el filtro de la Prensa Asociada, con sede en Estados Unidos y única fuente internacional con la que contaba el periódico.
\end{abstract}

Palabras clave: prensa, guerra, tergiversación, agencias de prensa, Segunda Guerra Mundial.

\begin{abstract}
The objective of this text is to analyze the way in which the Diario de Costa Rica treated the main events of World War II between 1939 and 1945. The 14 fundamental moments were selected: the invasion of Poland, the declaration of war of France and England, the German invasions to the north and east of Europe, the fall of Paris to the Germans, the armistice and occupation of France, the invasion of Russia, the attack on Pearl Harbor, the landing and battle of Normandy, the liberation of Paris, the death of Mussolini, the capitulation of Germany and the atomic bombing of Hiroshima and Nagasaki. Methodologically, these facts were reported in high-level academic studies and contrasted with what was pointed out by the newspaper. The result is an obvious misrepresentation of the information that also came biased by the filter of the Associated Press, based in the United States and the only international source that the newspaper had.
\end{abstract}

Keywords: press, war, misrepresentation, press agencies, World War II. 


\section{Introducción}

La Segunda Guerra Mundial, la cual mantuvo la atención mundial durante más de seis años, afectó todos los ámbitos y relaciones en el globo y también dejó una importante huella en el periodismo y en la comunicación en términos generales. Así pues, la inmediatez se convirtió en una necesidad que se tenía que abordar urgentemente. Los espectadores, en todas partes del mundo, seguían los sucesos con avidez, en parte porque afectaba las relaciones comerciales, la política nacional e internacional, hacía mella en las relaciones sociales y alteraba la cultura y la religión, y también porque era un espectáculo macabro y sangriento que atraía el morbo humano.

Durante esos seis años se gastaron litros de tinta y toneladas de papel para exponer lo que acontecía en las páginas de los periódicos de todo el mundo, en Oriente y Occidente. Se ensayaron diversas formas de atraer y convencer a la opinión pública. En esta tarea, las agencias internacionales de noticias, como lo experimentaron durante la Gran Guerra, jugaron un papel clave como voceros de sus países de origen. La fotografía tuvo un rol fundamental para exponer los hechos y los adelantos tecnológicos, en particular el uso de los teléfonos y los radiotransmisores, fueron decisivos para el logro de la inmediatez noticiosa. Los periódicos se diagramaron con cuidado, destacando en negrita lo que consideraban que lo ameritaba, según los intereses. Se destinaron periodistas únicamente para trabajar las noticias internacionales. Estos hombres se nutrían de los datos que proporcionaban los cables que emitían las agencias internacionales de información y con ellos redactaban ensayos, crónicas, noticias o reportajes. Esto constituía un cambio fundamental con respecto de lo que ocurrió durante la Gran Guerra, pues entonces, los encargados de los periódicos publicaban los cables tal y como llegaban al teletipo.

Este no fue el único cambio. Si durante la denominada luego Primera Guerra Mundial, la forma de hacer periodismo varió definitivamente no solo a nivel de formato, sino también de contenido, es posible que durante la Segunda Guerra, en la que la comunicación jugó un papel central durante todo el conflicto, también ocurrieran transformaciones. Una de las afirmaciones que se suceden en los estudios sobre comunicación (especialmente prensa) y Segunda Guerra Mundial, es que hay un claro distanciamiento entre lo expuesto en los medios de comunicación y lo acontecido. Esta afirmación es cierta en países europeos y algunas naciones de América Latina y en Estados Unidos.

El objetivo de este trabajo es entonces detectar cambios en la forma de hacer periodismo en el Diario de Costa Rica, el principal periódico de circulación diaria en Costa Rica durante la Guerra, y explicarlos, considerando el impacto posible sobre los lectores, pero además, determinar la tergiversación informativa en las publicaciones periodísticas divulgadas por ese periódico. 
Para cumplir con ese propósito, se consideraron 14 de los principales hechos que se sucedieron durante la Segunda Guerra Mundial, los más decisivos en el conflicto y se buscó, en los periódicos de esas fechas, la noticia referente al suceso en particular. Lo expuesto en la prensa se contrasta con los estudios históricos de alto nivel académico que tratan el incidente y de esa manera se determina el apego o la lejanía de lo expuesto con lo acontecido.

Durante la Guerra hubo muchos eventos decisivos que determinaron el rumbo del conflicto. De todos estos destacan 14 que captaron la atención mundial por el impacto y las consecuencias que generaron en la evolución del conflicto:

- La invasión de las tropas alemanas a Polonia el 1 de septiembre de 1939.

- La declaratoria de guerra de Francia y Gran Bretaña a Alemania el 3 de septiembre de 1939.

- La invasión alemana al norte de Europa el 9 de abril de 1940.

- La invasión alemana al oeste de Europa el 10 de mayo de 1940.

- La caída de París en manos de los alemanes el 14 de junio de 1940.

- La aceptación del mariscal Philippe Pétain (jefe de Estado de la Francia de Vichy del 11 de julio de 1940 al 25 de agosto de 1944) del armisticio, el 17 de junio de 1940.

- La ocupación de Francia por Alemania el 22 de junio de 1940.

- La invasión de Alemania a Rusia en la operación "Barbarroja" el 22 de junio de 1941 y la victoria soviética en Stalingrado donde se capturaron más de 100000 prisioneros alemanes, el 2 de febrero de 1943.

- El ataque de Japón a Pearl Harbor el 7 de diciembre de 1941.

- El desembarco aliado en Normandía, el 6 de junio de 1944.

- La batalla de Normandía y la liberación de París, el 25 de agosto de 1944.

- La muerte de Benito Mussolini el 30 de abril de 1945.

- Capitulación de Alemania el 8 de mayo de 1945.

- El bombardeo atómico de las ciudades japonesas de Hiroshima y Nagasaki el 6 y 9 de agosto de 1945.

Se buscaron en el Diario de Costa Rica, el de mayor venta entonces en el país, cada uno de los hechos reseñados en la lista anterior; se extrajeron las informaciones, se estudió su contenido y se contrastaron con lo expuesto en los textos académicos. Se trata de la aplicación de la técnica de ir del texto al contexto y del contexto al texto.

Es preciso indicar que la agencia de prensa que nutría al Diario de Costa Rica de informaciones internacionales era la Prensa Asociada (PA) que era una empresa respaldada por los grandes consorcios periodísticos estadounidenses y, además, vinculada con la United Fruit Company (UFCO) que es la que selecciona y transmite los cables que llegan al país. 


\section{Invasión a Polonia y declaratoria de Guerra}

La comunicación fue un arma efectiva en demasía en la invasión de Alemania a Polonia a través del Danzig el 1 de setiembre de 1939. Los alemanes se presentaron como defensores del pueblo polaco a través en una estrategia que les resultó exitosa, a pesar de que debieron ajustarla durante el proceso. Su plan era vestir a alemanes convictos con el uniforme del ejército polaco, matarlos y hacer creer a la opinión pública, a través de la prensa, que se trataba de militares polacos que pretendían atacar la estación de radio Gleiwitz y que fueron socavados por los alemanes. De esta manera el fin último era demostrar que los germanos habían evitado el flagelo a favor el pueblo polaco. Esta propuesta es absolutamente coincidente con la característica esencial del nazismo: la mentira y el engaño (Solar).

Para infortunio de los alemanes, no lograron su cometido y la opinión pública recibió el mensaje contrario al planeado. Los germanos fueron vistos como los invasores. La prensa costarricense no fue la excepción. Reaccionó de inmediato reproduciendo los cables que llegaban de la agencia de noticias AP, a favor del pueblo polaco; se exponían sendas páginas asegurando el triunfo de Polonia sobre el invasor.

Ciertamente la acción alemana fue efectiva y rápidamente vencieron a los polacos. El 7 de septiembre de 1939, el gobierno y el ejército de Polonia no resistieron más y se rindieron ante los invasores. A diferencia de lo que acontecía, el Diario de Costa Rica lanzaba un titular de primera página asegurando que los polacos mantenían a los alemanes al norte de Varsovia. Ese mismo día, los franceses ingresaron 8 kilómetros en territorio alemán sin disparar un solo tiro. El Diario de Costa Rica destacaba que los franceses no solo atacaron sino que vencieron fácilmente a los alemanes obligándolos a huir (Diario de Costa Rica, 9-9-1939, 1).

Al siguiente día, la ocupación nazi era absoluta, tanto que el gobierno de Varsovia se refugió en Rumanía. El diario costarricense aseveró que el gobierno polaco estaba tomando posiciones arrebatadas por los alemanes.

Además de no informar sobre las minas sembradas por los alemanes que mataron a cientos de miembros del ejército francés, aseguraban que Gran Bretaña hundió a 6 o 7 submarinos alemanes cuando, en realidad, en el ataque naval que inicia Hitler, logra hundir en una semana 9 naves británicas. De hecho, esta operación, denominada Tannenberg, cobró cerca de 50 mil vidas (Ruiz 17).

Respecto a la declaratoria de guerra de Francia y Gran Bretaña a Alemania, el diario costarricense lo anunció con sirenas que despertaron a la población josefina y a las poblaciones ubicadas en las principales ciudades fuera del área metropolitana -donde el periódico tenía corresponsales-, unas horas antes de confirmarse la declaratoria. Su anuncio tuvo tal impacto en la población que, antes del aura, se agruparon 
frente al edificio que albergaba el periódico cientos de personas ávidas de conocer detalles de lo que acontecía en Europa (Diario de Costa Rica, 04-09-1939, 1).

Los reporteros costarricenses insistían en la fortaleza de las dos potencias con las que Costa Rica mantenía estrecho vínculo: Francia y Gran Bretaña, y su acción inmediata en defensa de Polonia, tal y como lo habían prometido. No obstante, es indiscutible la inacción de Francia y Gran Bretaña ante el ataque alemán; de hecho, incumplieron su promesa. Trataron de ocultar su actuación realizando algunos movimientos que no los comprometían ni los afectaban. El periódico, al contrario, subrayaba que ambas potencias estaban derrotando a los alemanes sin dificultad, cuando en realidad Alemania ganaba la guerra desde el principio (Diario de Costa Rica, 05-09-1939, p. 1). Similar fue la posición de la prensa en México. El periódico La prensa, del 5 de septiembre de 1939, destacaba con letras en rojo: "Sangrientos combates en todos los frentes por tierra, aire y mar" (y en negro resaltado agregaban) Francia en Inglaterra en acción" (De memoria 1).

\section{Alemania invade el norte y oeste de Europa}

Alemania invadió Noruega por el extremo norte y sur, en las ciudades costeras de Narvik y Oslo el 10 de abril de 1940. A pesar de la acción de los aliados, con apoyo polaco, “La victoria alemana en Noruega aseguró el acceso de la marina alemana al Atlántico Norte, especialmente el acceso de la flota de submarinos, y salvaguardó los transportes del mineral de hierro sueco para la industria bélica de Alemania Invasión alemana a Noruega: Narvik".

El 10 de abril de 1940, el Diario de Costa Rica titulaba la noticia principal con una frase informativa: “BATALLA NAVAL DE GRANDES PROPORCIONES EMPEÑADA ANOCHE EN AGUAS DE NORUEGA". Advertía que se trataba de una acción que podría ser "decisiva en el resultado de la guerra actual", pero indicaba que ya estaba por realizarse "una expedición militar aliada a Noruega, con los contingentes que se habían dispuesto para Finlandia". De hecho decía:

El ministerio de Relaciones Exteriores de Inglaterra dio ayer seguridades de ayuda a Noruega y declaró que ambas naciones lucharían unidas hasta conquistar la victoria. Si la flota inglesa consigue el dominio de la entrada del Báltico, la aventura de Noruega culminará en un tremendo desastre para Alemania (Diario de Costa Rica, 10-04-1940, 1).

El 4 de junio, tras intensas luchas navales, las tropas aliadas evacuaron Noruega y, tres días después, el rey de Noruega y su gobierno se exilió en Londres. Para el 9, salieron las últimas tropas británicas mientras los franceses lo habían hecho desde mayo, cuando la ofensiva alemana contra Francia fue tomando matices cada vez más violentos y decisivos a favor de los germanos. 
Como se expone en la Figura 1, el periódico costarricense destaca en el titular del 5 de junio otro escenario: los bombardeos aéreos a París por el ejército alemán. En los subtítulos, sin embargo, admiten que "Dunquerque fue al fin capturado ayer por los alemanes después de haber sido destruido y abandonado por las últimas tropas aliadas" $\mathrm{y}$, haciendo alusión a un comunicado alemán, admiten que estos capturaron cuarenta mil prisioneros y un gran botín de guerra. A renglón seguido, subrayan que en un discurso Winston Churchill externó la decisión de Inglaterra "de continuar luchando hasta la victoria", mientras Hitler también juraba "llevar la guerra hasta la final y completa aniquilación de todas las fuerzas aliadas", en otros términos, Inglaterra se defenderá mientras Alemania amenaza con "aniquilar" (Diario de Costa Rica, 05-06-1940, 1).

Figura 1

LOS BOMBARDEOS AÉREOS A PARÍS POR EL EJÉRCITO ALEMÁN

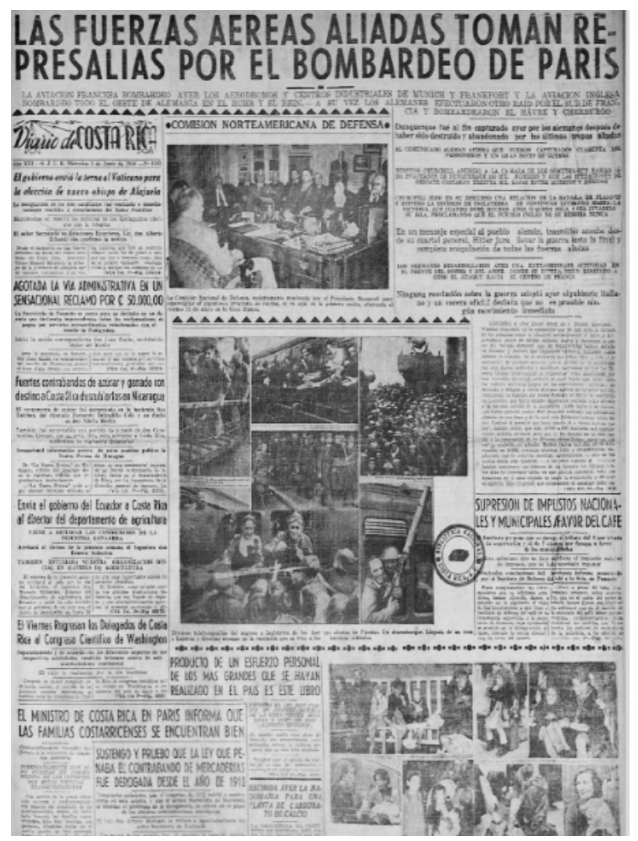

Fuente: Diario de Costa Rica. 05-06-1940, 1.

\section{La caída de París, armisticio y la toma de Francia}

Ciertamente la prensa no creía que París, luego de intensas batallas, cayese en manos de los alemanes como ocurrió el 14 de junio de 1940. 
En concordancia con lo que divulgaban las agencias de noticias, El Diario de Costa Rica se negaba a reconocer que los alemanes hubiesen sido capaces de capturar la capital europea por antonomasia. El 15 de junio exponen una composición gráfica de letras donde se destaca, como se aprecia en la Figura 2, que la batalla continúa aunque, en letra pequeña, reconocen que París fue tomada. Esto realmente no sucedió de esa manera. Ciertamente hubo escaramuzas y se desarrolló una compleja resistencia clandestina, pero ya Francia no tenía capacidad para enfrentarse al enemigo a partir del 15 de junio.
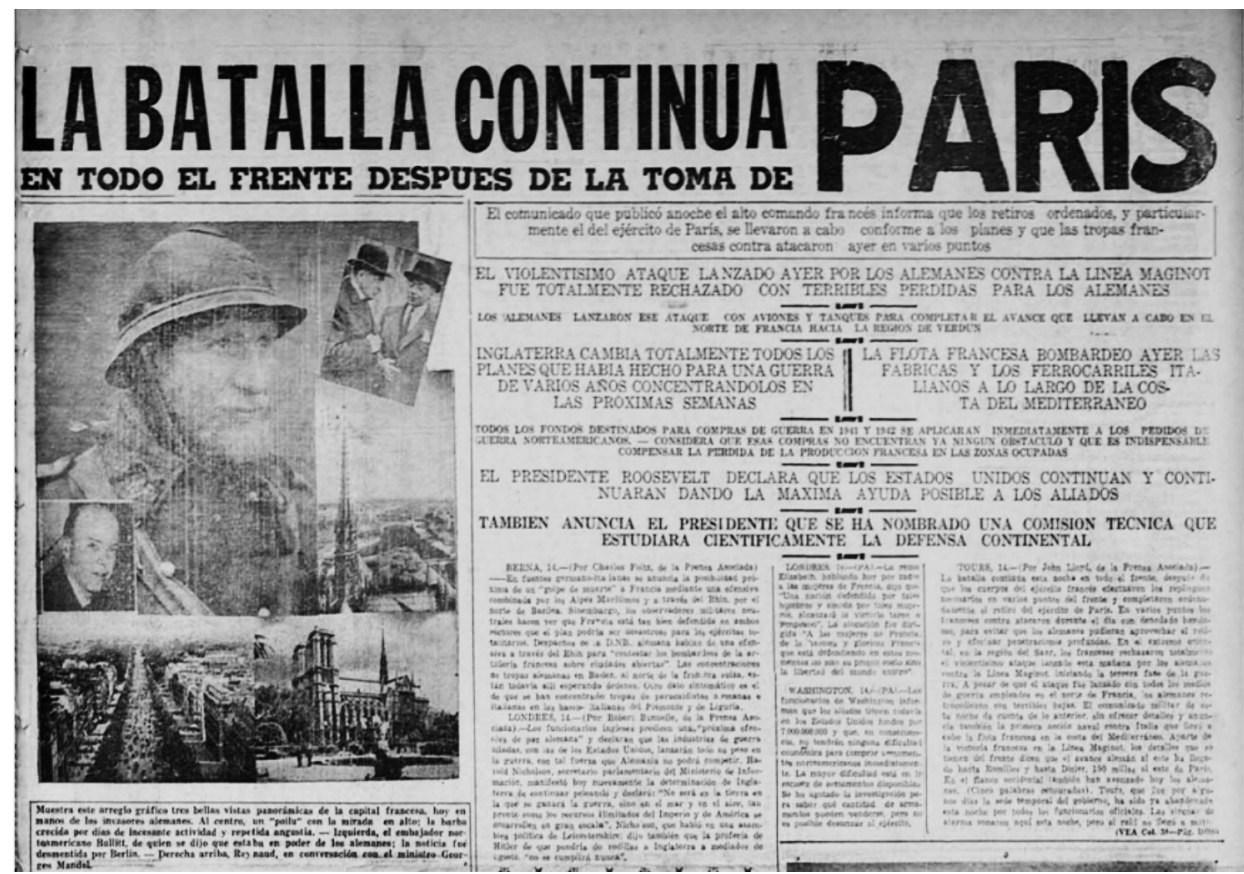

Fuente: Diario de Costa Rica, 15-06-1940, 1.

Los subtítulos confirman la intencionalidad del diario: de los ocho apartados principales de la primera página, solo uno hace referencia al avance alemán y siete confirman el progreso de los franceses o las acertadas acciones de los aliados (Tabla 1). 
Tabla 1

CLASIFICACIÓN DE LOS SUBTÍTULOS DEL DIARIO DE COSTA RICA (14-6-1940)

$\begin{array}{ll}\text { Titular } & \begin{array}{l}\text { Avance Avance Acciones } \\ \text { francés alemán aliadas }\end{array}\end{array}$

El comunicado que publicó anoche el alto comando francés informa que los retiros ordenados, y particularmente el del ejército de París, se llevaron a cabo conforme a los planes y que las tropas francesas contra atacaron ayer en varios puntos.

El violentísimo ataque lanzado ayer por los alemanes contra la línea Maginot fue totalmente rechazado con terribles pérdidas para los alemanes.

Los alemanes lanzaron ese ataque con aviones y tanques para completar el avance que llevan a cabo en el norte de Francia hacia la región del Verdún.

Inglaterra cambia totalmente todos los planes que había hecho para una guerra de varios años concentrándolos en las próximas semanas.

La flota francesa bombardeo ayer las fábricas y los ferrocarriles italianos a lo largo de la costa del mediterráneo.

Todos los fondos destinados para compras de guerra en 1941 y 1942 se aplicarán inmediatamente a los pedidos de guerra norteamericanos. Considera que esas compras no encuentran ya ningún obstáculo y que es indispensable compensar la pérdida de la producción francesa en las zonas ocupadas.

El Presidente Roosevelt declara que los Estados Unidos continúan y continuarán dando la máxima ayuda posible a los aliados.

También anuncia el Presidente que se ha nombrado una comisión técnica que estudiará científicamente la defensa continental.

Fuente: Elaboración propia. 
La Tabla 1 evidencia que en las informaciones que divulgó el periódico costarricense evita exponer a Francia derrotada ante el enemigo común y la lectura que se esperaba de parte del público era que los aliados iban en pos de recuperar París y derrotar al enemigo en todos los flancos. La participación de Estados Unidos se exponía como el derrotero final que conduciría a la victoria, no tanto por la participación de legiones, sino por el aporte económico que ofrecía a los aliados.

Además, la noticia se acompañó de una composición fotográfica en la que se destacaba un soldado francés, "con la mirada en alto, la barba crecida por días de incesante actividad y repetida angustia" (Diario de Costa Rica, 05-06-1940, 1).

Francia firma el armisticio el 22 del mismo mes aceptando que la mitad del territorio estaba en manos del Tercer Reich. El 8 de noviembre de 1942, dos años después, alemanes e italianos ocuparon la parte libre que quedaba de Francia. No será, sino hasta el 24 de agosto de 1944, cuando París fue liberado.

Los periódicos de los días anteriores a la firma del armisticio mencionaban a Francia y particularmente la inaceptabilidad de los términos del acuerdo que proponía Alemania. Ninguna nota hizo referencia a los efectos del ataque alemán sobre París, en vidas humanas y costos materiales, por ejemplo; pero en su lugar, destacaron el valor de los aliados y la fiereza con la que se enfrentaron y seguirían enfrentándose a los invasores. En otros términos, la toma de París provocó que la maquinaria de guerra inglesa, según las notas periodísticas, de superioridad no sobrepasada por potencia ninguna, se comprometió decididamente y de inmediato en la contienda contra Alemania.

A partir de entonces, la lucha se volvió encarnizada, de acuerdo con las informaciones que se divulgaban, donde Inglaterra siempre aventajaba en mucho a su enemigo. Por ejemplo, el 20 de junio de 1940, el diario destacó el siguiente texto:

En un extenso comunicado oficial el Ministerio de Aviación Inglés da cuenta detallada de los tremendos bombardeos que los aviones pesados de la R.A.F. han hecho durante tres noches consecutivas sobre el gran número de ciudades alemanas.

No se mencionan cuáles ciudades ni las consecuencias para ambos bandos. La ambigüedad en la redacción era la tónica en este tipo de noticias.

Llama la atención en la Figura 3 que en la gráfica (fotografías y composiciones fotográficas), sí se refiere a la presencia alemana en la capital francesa y lo evidencia el uso del símbolo nazi de la bandera con la esvástica, el aeroplano que aterrizó en la Plaza de la Concordia y el desfile de la caballería alemana con el emblemático arco del triunfo al fondo. 
Figura 3

PRESENCIA ALEMANA EN LA CAPITAL FRANCESA

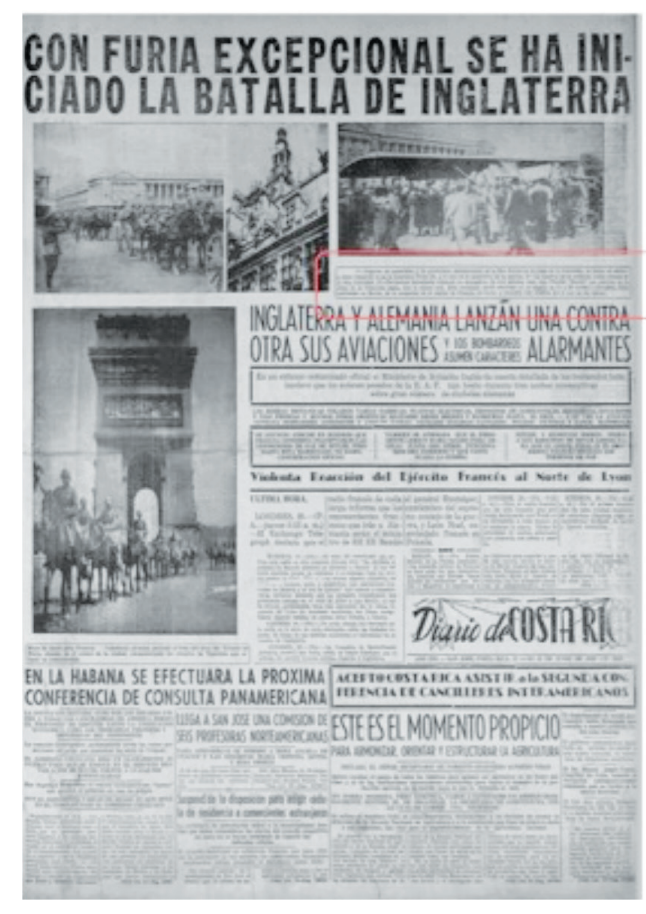

1. Vapores de materiales y de provisiones desembocando de la Rue Royale en la plaza de la Concordia. Al fondo, el edificio a mano izquierda es de la Guarany Trust $\mathrm{Co}$. Y el otro es el ministerio de la manina. 2. - La bandera de la esvástica ondea encima de la estela municipal. 3_Parisienses extrañados rodeando un aeroplano de tres asientos nazi, tipo Fleseler "Ethoreh" que aterrizo en la plaza de la Concordia según dice el censor nazi. Este aeroplano puede aterrizar en un espacio de 18 a 28 yardas._ (Primeras fotos publicadas en Berlin, de la ocupación de la capital de Francia enviadas a DIARIO DE COSTA RICA por la via aérea).

Fuente: Diario de Costa Rica, 20-06-1940, 1.

Leído a ojo de pájaro se trata de una invasión que rememora y compara la acción con el ingreso de Napoleón en el siglo XIX a París. La ocupación pacífica de Francia, seguida del armisticio, condujo a una división del país, más de palabra que de hecho, pues el régimen de Pétain, que se ejercía desde Vichy, siguió sin tardanza las directrices del mando alemán, entregando a ciudadanos judíos, comunistas y miembros de la resistencia (Sahores).

El día 22 se publicó la firma del armisticio y se destacó el reproche de Inglaterra al mariscal Pétain por haber aceptado los términos del acuerdo.

El Primer Ministro británico, Winston Churchill advertía en un comunicado, que divulgó Prensa Asociada, que si los términos del acuerdo de paz fuesen aceptados por todos los franceses:

Pondrían no solo a Francia sino al imperio francés, totalmente a merced y bajo el poder de los dictadores alemán e italiano. El pueblo francés está obligado a trabajar contra sus aliados y el suelo de Francia sería usado, con la aprobación del gobierno de Burdeos, como medio de atacar a sus aliados $y$, además, todos los recursos del imperio francés y la flota francesa pasarían 
rápidamente a manos del adversario para el cumplimiento de su propósito" (Diario de Costa Rica, 22-06-1940, 1).

Como una estrategia para levantar los ánimos, comúnmente utilizada en la Primera Guerra Mundial, las noticias sobre la toma de Francia y el armisticio eran seguidas de informaciones que aseveraban el triunfo inglés a corto plazo. En el siguiente párrafo es evidente esta maniobra informativa en la seguidilla de titulares:

Mientras el gobierno de Burdeos decreta el duelo nacional, Hitler en una proclama al pueblo da gracias a Dios por la victoria y decreta diez dias de fiesta nacional.

Las condiciones del armisticio se darán a conocer simultáneamente en Francia, Alemania e Italia cuarenta y ocho horas después de firmados los acuerdos.

\section{En Inglaterra es cada vez mayor la confianza del gobierno y del pueblo en la victoria final}

Inglaterra cuenta con los inagotables recursos de su imperio, con el dominio del mar, con el respaldo de los Estados Unidos, con el próximo dominio del aire y con la ayuda de la flota y de la mayor parte del Imperio francés (Diario de Costa Rica, 25-06-1940, 1).

En los días sucesivos continuó la misma tónica en las informaciones, apelando, cada vez con más frecuencia, a la presencia de los Estados Unidos en el conflicto apoyando a los aliados.

\section{La invasión de Alemania a Rusia: operación "Barbarroja"}

El 22 de junio de 1941, un año exacto después de la firma del armisticio en París, Alemania se aventura en una empresa que le costará caro: la invasión a Rusia, Barbarroja, como le llamó en clave el alto mando alemán, haciendo alusión a Federico I Barbarroja, I emperador del Sacro Imperio Romano Germánico del siglo XII (Canales y Del Rey).

Aunque al inicio lograron avanzar a pasos agigantados, dejando destrucción y desolación entre la población civil y los grupos militares, los alemanes se enfrentaron a tres enemigos importantes: el ejército, las guerrillas rusas y el clima.

Durante el año de 1941 Alemania estuvo a pocos kilómetros de Moscú e hicieron destrozos en Stalingrado y Leningrado. Incluso en octubre de 1941 la ofensiva de la Wehrmacht (ejército alemán) estuvo a 25 kilómetros de Moscú lo que condujo a la evacuación masiva de la ciudad el 17 de octubre del mismo año. El invierno les impidió tomar Moscú. La prensa se limitó a no dar ninguno o proporcionar pequeños pincelazos de lo que acontecía. 
En el periódico costarricense publicado el 22 de junio de 1941, el cual anunciaba la invasión alemana a Rusia, evidenciaba reticencia a defender a la Unión de Repúblicas Socialistas Soviética (URSS), como si lo hace cuando trata asuntos que involucran a Gran Bretaña o a Francia (Figura 4).

Figura 4

\section{DECLARACIÓN DE GUERRA ALEMANA}

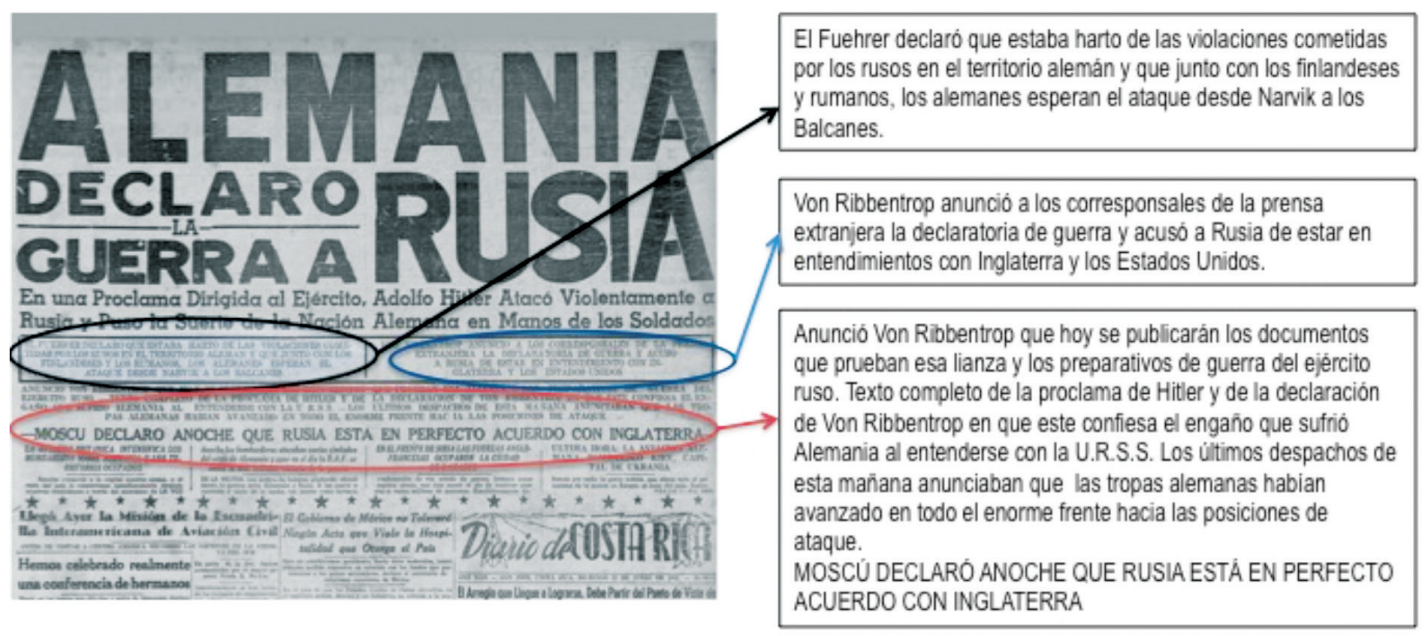

Fuente: Diario de Costa Rica. 22-6-1941, 1.

Esta ambivalencia inicial se debe a que el 23 de agosto de 1939, pocos días antes de iniciarse la Segunda Guerra Mundial, la Alemania Nazi y la Unión Soviética habían firmado el Pacto Ribbentrop-Mólotov en el cual destacaban las cláusulas de no agresión mutua y el interés de estrechar vínculos económicos con tratos preferenciales, además, y quizá el más importante, se comprometían ambos a no hacer alianzas políticas o militares contraria al otro. Adicional, en un protocolo secreto, ambos establecían sus límites de influencia en zonas específicas, en las que ninguno podría intervenir.

El pacto causó conmoción en Europa en cuanto significaba que dos ideologías contrarias llegaran a un acuerdo. A pesar del asombro, los partidos comunistas de Europa con clara influencia soviética (Francia y Reino Unido) apoyaron la orden de Stalin y se negaron a luchar contra el Tercer Reich.

Adicionalmente y para sorpresa de muchos, la Unión Soviética no solo no condenó la invasión de Alemania a Polonia, sino que se lanzó contra ella 16 días después. La URSS invadió luego Finlandia y se anexionó Estonia, Lituania, Letonia y algunos territorios rumanos.

Hitler no tenía intención de respetar el Pacto pues su interés era expandir el territorio alemán hacia el Este. Finalmente, el 22 de junio de 1941 invade territorio soviético. 
El Diario de Costa Rica del 22 de junio de 1941 únicamente expone la posición alemana haciendo clara alusión a la traición rusa al Pacto firmado, entre tanto los periódicos mexicanos ese mismo día informaron en sus portadas que Alemania había atacado a la Unión Soviética. Los periódicos independientes celebraron el suceso y El Popular (comunista) mostró cierto alivio debido a que la URSS se deslindó de cualquier apoyo a Alemania (Peredo).

Para octubre y especialmente para noviembre de 1941, la situación en Rusia era un verdadero caos:

La actuación alemana, la de sus aliados en la zona, la de los rusos y la de los partisanos, sería implacable. Unidades de Einsatzgruppen y de las Waffen SS volksdeutsche recién creadas, sembraron el pánico en las comunidades campesinas a las que a menudo acusaban de apoyar a los guerrilleros. Destruyeron, incendiaron y cometieron todo tipo de actos brutales (Canales y Del Rey 175).

Efectivamente, las respuestas de los germanos contra los partisanos (movimiento guerrillero soviético) fueron bestiales: torturas, ejecuciones con empaladas, crucifixiones, castraciones, decapitaciones, etc., durante cuatro años. De esto la prensa no informó nada.

A la Prensa Asociada, agencia que le vende los servicios al Diario de Costa Rica como se ha mencionado, se le acusa de haber colaborado con el gobierno nazi y ocultado atrocidades del régimen, por lo menos en España y Portugal, como sucede en Costa Rica (Lizarazo).

El 4 de diciembre de 1941, hay un repunte en la contraofensiva rusa y el periódico costarricense destaca con su titular principal "Mejora notablemente la situación de las fuerzas rusas en Moscú". Aseveran que, al sur de la ciudad, "quedó definitivamente deshecha la ofensiva alemana. Lo rusos siguen reconquistando territorio" y que tanto en el oeste como en el noroeste fueron rechazados todos los ataques nazis (Diario de Costa Rica, 04-12-1941, 1).

El 13 de diciembre de 1941, el Diario de Costa Rica destaca el siguiente titular: "Rusia anuncia oficialmente la completa derrota y desintegración del ejército de 750.000 hombres que tenían los alemanes en Moscú, que ha tenido ochenta y cinco mil muertos en las últimas semanas" (Diario de Costa Rica, 13-12-1941, 1).

En diciembre de 1941, tanto Alemania como Japón inician lo que será su derrota definitiva cuatro años después, tiempo en el cual hubo muerte y destrucción sin piedad. El invierno ruso, como sucedió con Napoleón, frenó el avance alemán.

Ciertamente la guerra entre Alemania y Rusia estaba lejos de terminar y tampoco era real que Alemania fuese derrotada. Para el 18 de agosto de 1942, el General Friederich Poulus estaba a 55 kilómetros de Stalingrado y los germanos bombardearon sin clemencia Stalingrado en septiembre de 1942. El Diario de Costa Rica informa que 
"los rusos mantienen todas sus posiciones en el arco de Stalingrado" (Diario de Costa Rica, 08-09-1942, 1).

A renglón seguido aseveran que la aviación americana está evidenciando su superioridad sobre todos los territorios ocupados por los alemanes.

En enero de 1943, los soviéticos empiezan su avance imparable. Se inicia el triunfo en Stalingrado -en febrero de 1943 se rinden los Nazis en Stalingrado- y, un año después, la derrota alemana era innegable. Ahora sí el diario costarricense destaca los triunfos de la URSS (Figura 5).

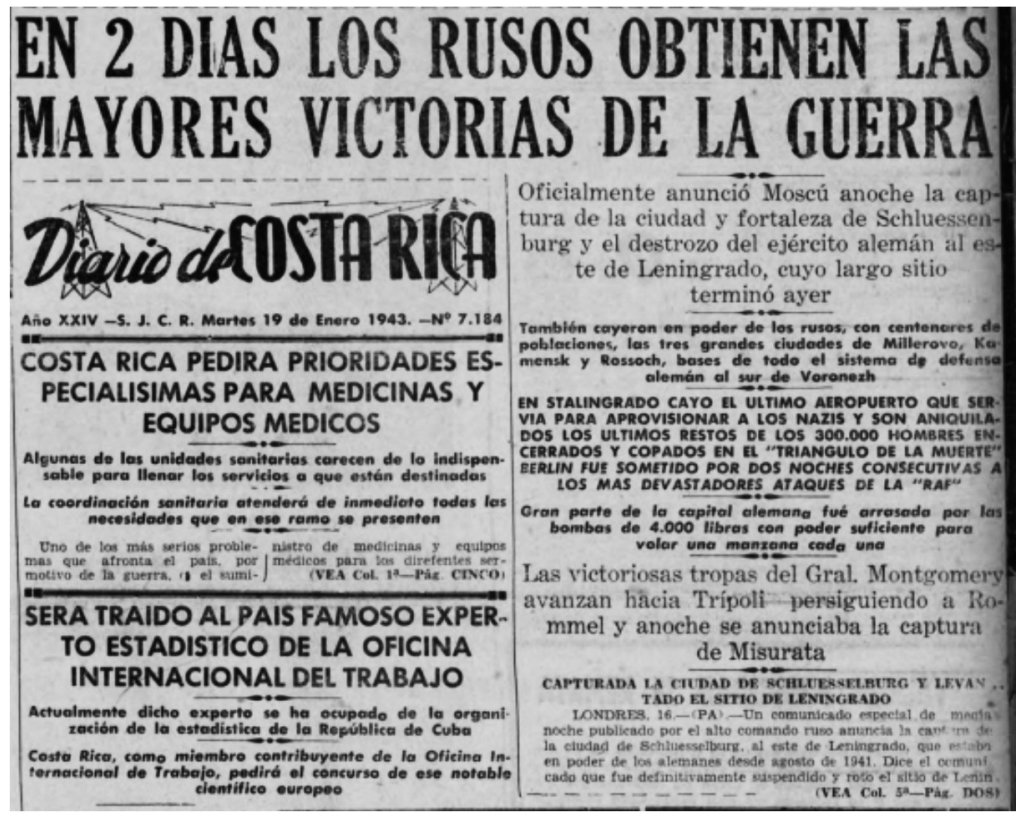

Fuente: Diario de Costa Rica, 19-1-1943, 1.

La insistencia de la tergiversación de las informaciones por parte de la prensa es un fenómeno frecuente también en otros países. En España, donde el régimen de Franco apoyaba solapadamente a Alemania "si los rusos reconquistaban una ciudad, o bien Montgomery batía a Rommel, tenía un valor inestimable para la propaganda alemana poder reproducir una opinión española afirmando que la cosa no tenía la menor importancia" (Schulze, 1995, 215). Incluso, durante la invasión a Rusia, la prensa canaria responsabilizó a Rusia de todos los males de la Guerra Civil Española y por tanto justificaban la acción alemana. Más aun, "se le atribuyó exclusivamente a la URSS la 
responsabilidad de la agresión alemana, también se hizo lo mismo con EE. UU. tras el ataque japonés a Pearl Harbor" (Díaz Benites 1052).

Para entonces Estados Unidos había ingresado a la guerra a favor de los aliados. Aunque su presencia estuvo desde el inicio de la contienda, no será sino hasta el ataque de Japón a la base militar de Pearl Harbor que no se toma la decisión definitiva.

\section{Estados Unidos entra en la guerra}

El 7 de diciembre de 1941, la aviación japonesa ataca la base americana de PearlHarbor, ubicada en Hawai. Esto condujo de inmediato a la declaratoria de Guerra de Estados Unidos a Japón.

El día 9 de diciembre, el Diario de Costa Rica "puntualiza los acontecimientos que culminaron con la declaratoria de guerra [de Costa Rica] a Japón".

A nivel mediático, el Diario de Costa Rica contaba con diferentes plataformas a través de las cuales divulgaba las noticias: Pizarras informativas ubicadas en las paredes del edificio que albergaba al periódico y a la radio. Por una parte, los manifestantes y curiosos se congregaban en las calles aledañas al edificio que alojaba al periódico -era el sitio de reunión, en este caso para expresar su solidaridad con el pueblo y el gobierno de los Estados Unidos-. También acudían para enterarse, desde las pizarras informativas, de los últimos acontecimientos del conflicto bélico que mantenía al mundo perturbado desde hacía 2 años. Además, combinaba la información que exponía a través del periódico con la emitida a través de la radio Voz de la Víctor, propiedad de los dueños del Diario de Costa Rica, con lo que "han tenido al tanto al país, minuto a minuto sobre todos los acontecimientos nacionales e internacionales" (Diario de Costa Rica, 09-12-1941, 1).

El proceder informativo, tras el ataque japonés, fue el siguiente:

Inmediatamente después de que este periódico tuvo conocimiento del ataque japonés a las posesiones norteamericanas de Hawai y Filipinas, consignamos ese mensaje cablegráfico en nuestras pizarras y suministramos a través del micrófono de LA VOZ DE LA VÍCTOR, micrófono por el cual mantuvimos durante todo el día y la noche del domingo, un constante servicio informativo, de prontitud y veracidad inigualables (Diario de Costa Rica, 09-12-1941, 1).

El mismo 9 de diciembre, el periódico destacó la declaratoria de guerra de Costa Rica a Japón, por acuerdo legislativo, y el encarcelamiento de japoneses -que estaban en el puerto de Puntarenas- en la penitenciaria ubicada en San José. De esta manera demostraban la participación decidida del país en el conflicto.

La declaratoria de Estados Unidos al Eje se anunció el 11 de diciembre de 1941 en la segunda página del periódico, a través únicamente de un titular, sin más. De hecho, en una segunda edición del periódico ese día se anuncia que "la declaratoria de guerra del Eje a Estados Unidos se considera inminente” (Diario de Costa Rica, 11-12-1941, 1). 
Justo en la tarde del día 11 de diciembre, Hitler explicó al Reichstag las razones por las que Alemania debía declarar la guerra a los Estados Unidos (Canales y Del Rey).

A partir del ingreso de Estados Unidos en la guerra, las notas divulgadas por el Diario de Costa Rica los días siguientes se volcaron a destacar el avance de los soldados estadounidenses. A partir de entonces el periódico recurre, cada vez con más frecuencia, al uso de imágenes gráficas elaboradas para mostrar a los lectores los movimientos bélicos (Figura 6), una práctica ensayada ya durante la Gran Guerra que ahora se usa con frecuencia.

\author{
Figura 6 \\ MOVIMIENTOS BÉLICOS
}

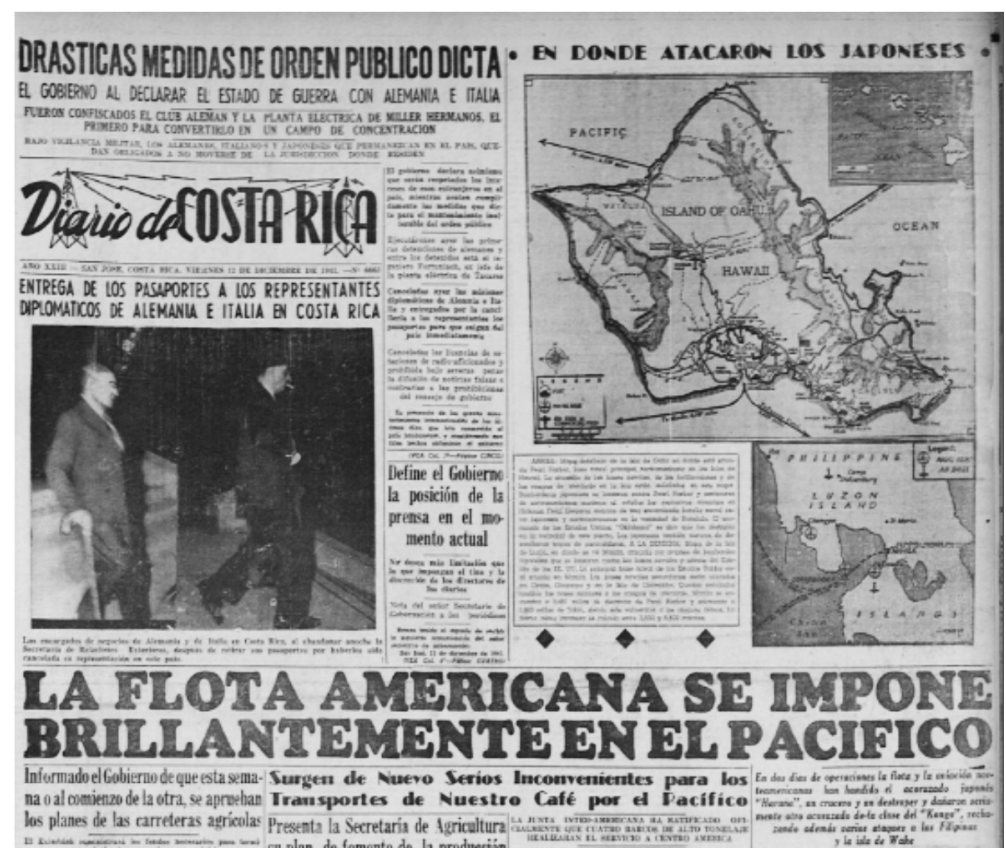

Fuente: Diario de Costa Rica. 12-12-1941, p. 1.

En efecto, el ingreso oficial de Estados Unidos significó un antes y un después en la Guerra:

En 1942, el Eje aún logró triunfos espectaculares y, sin embargo, la realidad histórica crucial es que los altos funcionarios del Tercer Reich consideraron, ya en diciembre de 1941, que era imposible obtener la victoria militar al no haber logrado derrotar a la URSS (Altares párr. 2) [y por la inyección de soldados y armas que aportaba Estados Unidos]. 
El periódico costarricense continuaba reproduciendo los cables que resaltaban solo triunfos de los aliados. El 10 de diciembre de 1941, titulaba la noticia principal "RECHAZADO EL ATAQUE JAPONES A LA COLONIA BRITÁNICA DE HONG KONG" (Diario de Costa Rica, 10-12-1941, 1). Ocurrió exactamente lo contrario: Los japoneses atacaron por aire, tierra y agua a Hong Kong sin descanso durante 18 días. Ya el 25 de diciembre, los británicos no tenían nada que hacer ante un triunfante enemigo y se rindieron (Suárez). El Diario de Costa Rica del día 25 informó sobre la situación en Hong Kong afirmando que "LA GUARNICIÓN DE HONG KONG RECHAZA A LOS JAPONESES. Aparentemente los japoneses sienten ya la presión de la ofensiva china que se halla a 30 millas de Hong Kong" (Diario de Costa Rica, 25-12-1941, 1). En otros términos, tergiversa la información a favor de los aliados. Pero al día siguiente, no tuvo más que aceptar la derrota. Como se observa en la Figura 7, todas las notas (10) de primera página exaltan el valor y el avance aliado, excepto dos, la concerniente a la derrota de Hong Kong y otra referente a la batalla en Filipinas donde los japoneses "han avanzado en dos puntos a pesar de la resistencia de las tropas americanas" (Diario de Costa Rica, 27-12-1941, 1).

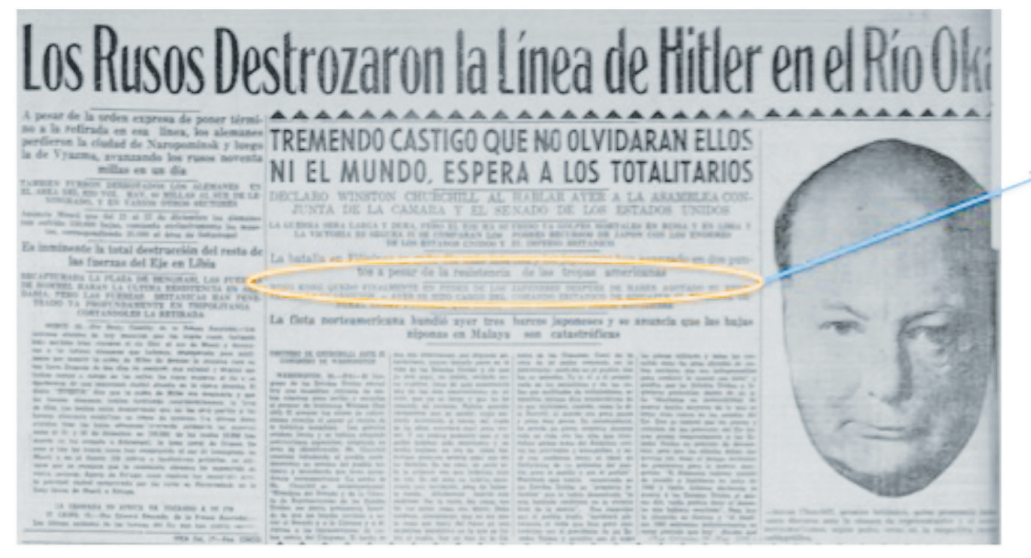

Hong Kong quedó finalmente en poder de los japoneses después de haber agotado su resistencia la guarnición

Fuente: Diario de Costa Rica, 27-12-1941, p. 1.

La caída de Hong Kong significó un fuerte golpe para la marina británica, se trataba del centro del poder británico en Asia Oriental. El mismo 8 de diciembre, tras 16 días de ataque, los japoneses se hicieron con la isla Wake (Canales y Del Rey) infringiendo una grave derrota a los estadounidenses, situación que no se publicó en los diarios.

Lo cierto es que las derrotas de los aliados fueron ocultadas igual que los triunfos del Eje. 
Entre tanto, la prensa canaria -germanófila- aseveraba, tras el ingreso de Estados Unidos a la Guerra, que:

El presidente Roosevelt ha conseguido su principal objetivo. Ya está el mundo dividido en dos zonas hostiles e irreconciliables a pesar de los esfuerzos hechos por las naciones que sólo quieren trabajar y vivir y a las que en nombre la libertad se les han cerrado todos los caminos... Ya logró Franklin $D$ Roosevelt su objetivo. A un lado los dominadores del mar, los dueños del dinero y de las riquezas. Al otro los pueblos que trabajan y sufren y se ven impelidos a luchar por su libertad y por su vida (Díaz Benites 1052).

\section{Normandía 1944}

El 6 de junio de 1944, el conocido Día D, los aliados iniciaron el desembarco en las playas de Normandía.

La supremacía aérea anglo-norteamericana fue clave para entender el éxito de la operación. Los aviones aliados destrozaron la mayor parte de los puentes sobre el Sena y el Loira, impidiendo que los alemanes pudieran enviar refuerzos a Normandía. A ello se unió la dificultad de los alemanes en cubrir una costa de 4800 kilómetros de longitud entre la frontera española y Holanda y las continuas desavenencias y contradicciones en el mando militar alemán sobre dónde tendría lugar el desembarco y cómo se le debía hacer frente (Viana).

Como era de esperar, el Diario de Costa Rica le dio una cobertura enorme a la operación aliada:

\section{BRILLANTE ÉXITO CORONÓ EL PRIMER DÍA DE LA INVASIÓN}

250.000 hombres, 11.000 aviones, 4000 barcos y millares de embarcaciones enormes realizaron la mayor y más audaz operación anfibia de la historia.

---0---

Más de 20 millas de Normandía entre Cherburgo y El Havre, con una profundidad hasta de 10 millas quedaron firmemente en poder de las tropas anglo-americanas con muchas ciudades.

---0---

10.000 toneladas de bombas aéreas y el fuego de los acorazados americanos abrieron paso a la invasión, pero el mayor factor de éxito fueron cuatro divisiones de paracaidistas que dislocaron la retaguardia alemana.

---0---

El plan realizado fue el mismo que Eisenhower llevó a Inglaterra en 1942 y que le valió la jefatura suprema, pero se perfeccionó con la experiencia de África e Italia.

$---0---$ 
La radio alemana admite la captura de Caen, de Deauville de Homfleur, la constante ampliación de la cabeza de plaza y los inagotables refuerzos que siguen desembarcando.

---0---

Goering ordena a la Luftwaffe rechazar la invasión aunque sea destruida, pero sólo cincuenta aparatos nazis se enfrentaron ayer a más de once mil de los Aliados.

---0---

Mr. Winston Churchill, el generalísimo Eisenhower, el Presidente Roosevelt, y el general Montgomery expresan satisfacción plena por los resultados militares de ayer.

---0---

La captura de la ciudad de Caen indica que los Aliados avanzan hacia París. -En el frente de Italia el Quinto Ejército persigue al norte de Roma a los alemanes que huyen sin resistencia y desmoralizados. - Berlin teme de un momento a otro una gran ofensiva del ejército ruso.

---0---

Extraordinariamente bajas han sido las perdidas aliadas en la invasión.- Se perdió únicamente el $1 \%$ de los aviones participantes y las perdidas navales americanas se limitan a 2 destroyers $y$ 1 lancha de desembarque.

---0---

Bajo el supremo comando de Eisenhower operan el Gral. Montgomery como jefe de la infantería y tanques, el Gral. Spoatz como jefe de la aviación y el almirante Sir Bertram Ramsay como jefe de la flota._Berlín admite que la situación es grave y predice un ataque a París y próximos desembarques en varios puntos de la costa. _ En la conferencia de Therán y con la aprobación del Premier Stalin se fijaron para la invasión "los primeros días de junio" (Diario de Costa Rica, 07-06-1944, 1).

Los datos numéricos que divulgó el periódico son distintos a los que se contabilizan entre los implicados. La operación -la mayor por mar de la historia- movilizó 175000 soldados, 50000 vehículos, más de 5000 buques y 15000 aviones (Viana).

El periódico acompañó el texto con una composición fotográfica que evidenciaba lo expuesto referente al desembarco en Normandía (Figura 8). Con el mapa, ubicaba geográficamente al lector, en la parte superior situaba a los soldados en plena maniobra y, en la inferior, las lanchas utilizadas.

Si bien es cierto que a la postre la invasión fue exitosa, los alemanes defendieron sus posiciones provocando que "las playas [se cubrieran] de cadáveres y vehículos destrozados. En Omaha, por ejemplo, la oposición era muy superior a la que los veteranos soldados de la $1^{\circ}$ división estadounidense" (Canales y Del Rey 289). Sobre esto el periódico costarricense no informó. 


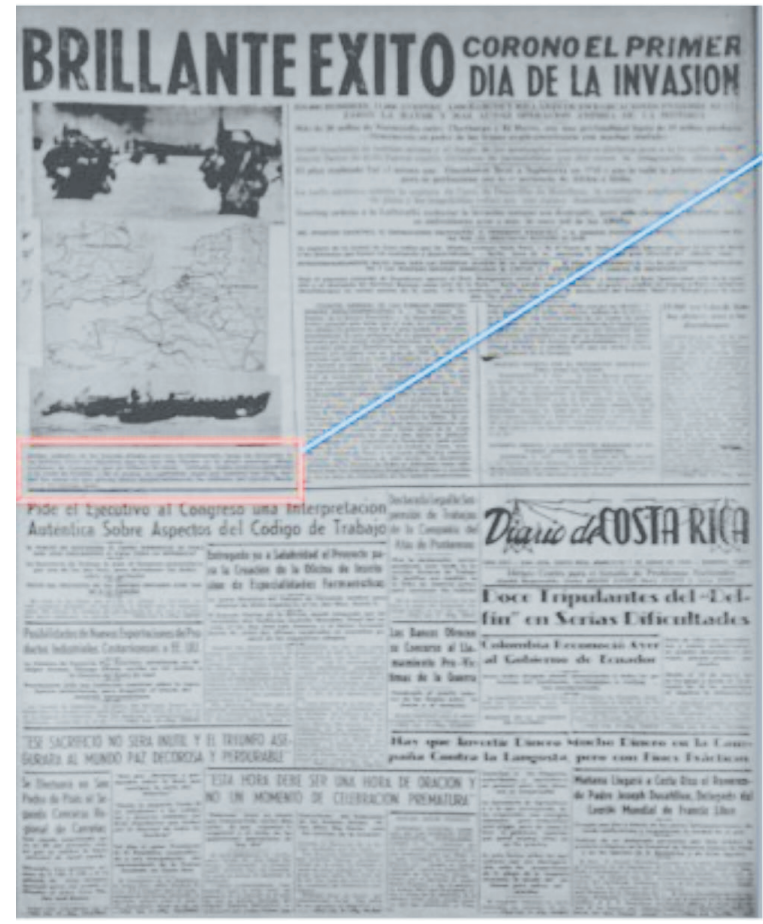

Arriba, soldados de las fuerzas aliadas avanzan decididamente, luego de descender de las lanchas, hacia los objetivos que les han sido fijados en la playa enemiga. Abajo, lanchones de transporte que en millares llevaron soldados anglo-américa-canadienses a la costa de Francia.- En el centro, un espléndido mapa que muestra con toda claridad las zonas en que pelean ahora encarnizadamente los soldados del ejército libertario de las fuerzas nazis.

Fuente: Diario de Costa Rica. 7-06-1944, 1.

De hecho, a finales de junio, las tropas estadounidenses habían ocupado posiciones claves y amenazaban con cercar a todo el ejército alemán y habían capturado 25000 prisioneros. No obstante, los británicos y canadienses, a las órdenes del General Montgomery, sufrían una fuerte resistencia para tomar la ciudad de Caen (Canales y Del Rey). No será sino hasta principios de agosto cuando los aliados vencen la férrea resistencia alemana y continuaron su paso hacia la liberación de París, que se hará efectiva el 25 de agosto de 1944.

El 26 el Diario de Costa Rica titulaba la noticia principal, ubicada al centro de la página: “Entusiasmo Emocionante, sin precedentes acogió la Entrada de los aliados a París". Exponía que las tropas americanas y francesas "entraron por la Porte d'Orleans a las 7.30 de la mañana".

La situación fue otra. París se sublevó el 13 de agosto para forzar a los aliados a liberar la ciudad. El General Leclerc, "ignorando las órdenes de sus superiores estadounidenses", envió ayuda para enfrentarse a la resistencia alemana en la ciudad. Los estadounidenses y 
los canadienses no tenían entre sus planes liberar Francia hasta varios meses después. No será sino hasta el día 16 de agosto, dado que el periódico no salió el día 15 por ser un día feriado, que el Diario de Costa Rica destacó el titular señalando "Liquidado el dominio alemán en todo el noroeste de Francia" (Diario de Costa Rica, 16-08-1944, 1).

No hay noticia alguna referente a la sublevación del 13 de agosto. Habrá que esperar hasta el día 15 cuando el periódico publica en primera página un pequeño párrafo que dice “De Gaulle ordena la sublevación total al pueblo francés y a las fuerzas de Maquis" (Figura 9) (Diario de Costa Rica, 15-08-1944, 1).

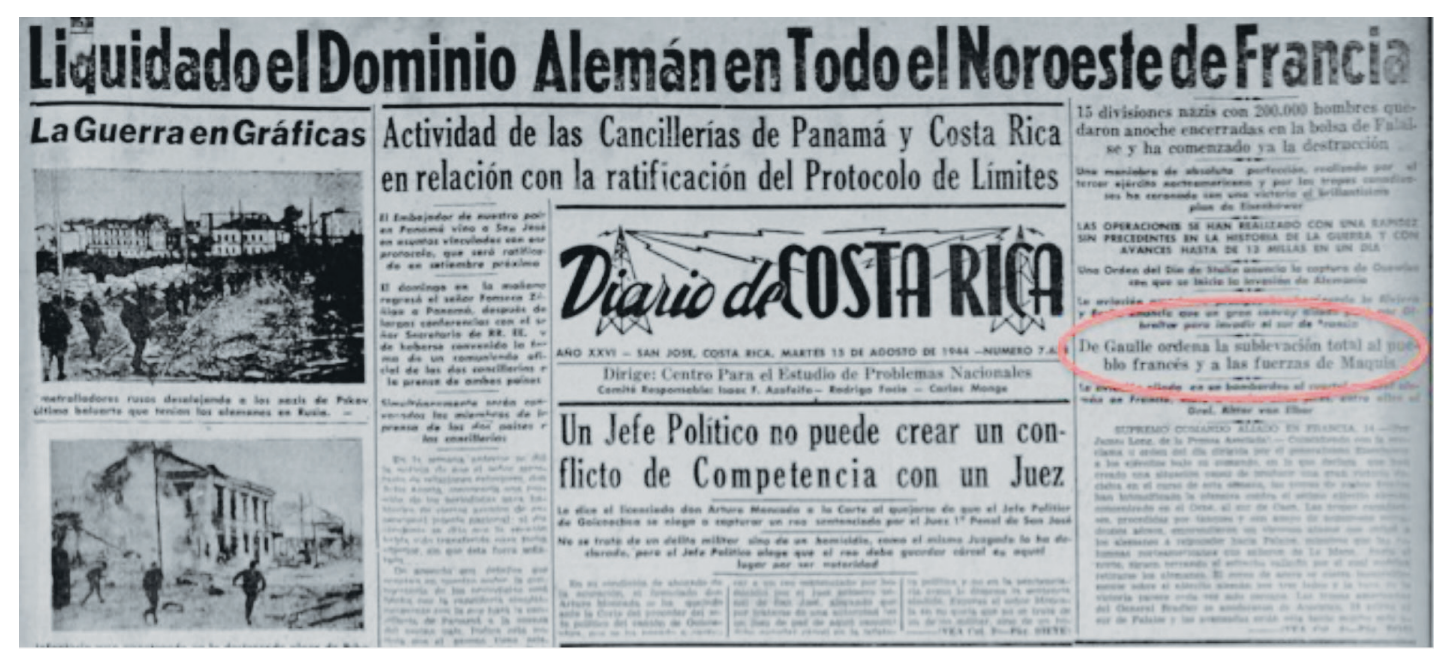

Fuente: Diario de Costa Rica, 15-08-1944, 1.

El 24 de agosto de 1944, el mismo día de la liberación de París, el Diario de Costa Rica anunció el hecho con el sonido de la sirena, el medio usado solo para avisar los principales hechos noticiosos. Con orgullo destacó en la primera página la siguiente leyenda, evidenciando su capacidad de inmediatez:

La sirena del Diario de Cosa Rica sí anunció a las 6 horas de ayer la caída de París en poder de las fuerzas patriotas de Francia. A las cuatro de la madrugada recibimos la primera noticia del suceso transmitida por la prensa asociada. Y no es culpa nuestra que "solo" "Diario de Costa Rica" tuviera el privilegio de esa primicia informativa sensacional.

Y continuaba la nota destacando detalles del suceso que, sin duda, significaba un triunfo ante las huestes germanas (Figura 10). 
Figura 10

COMPETENCIA POR INFORMAR

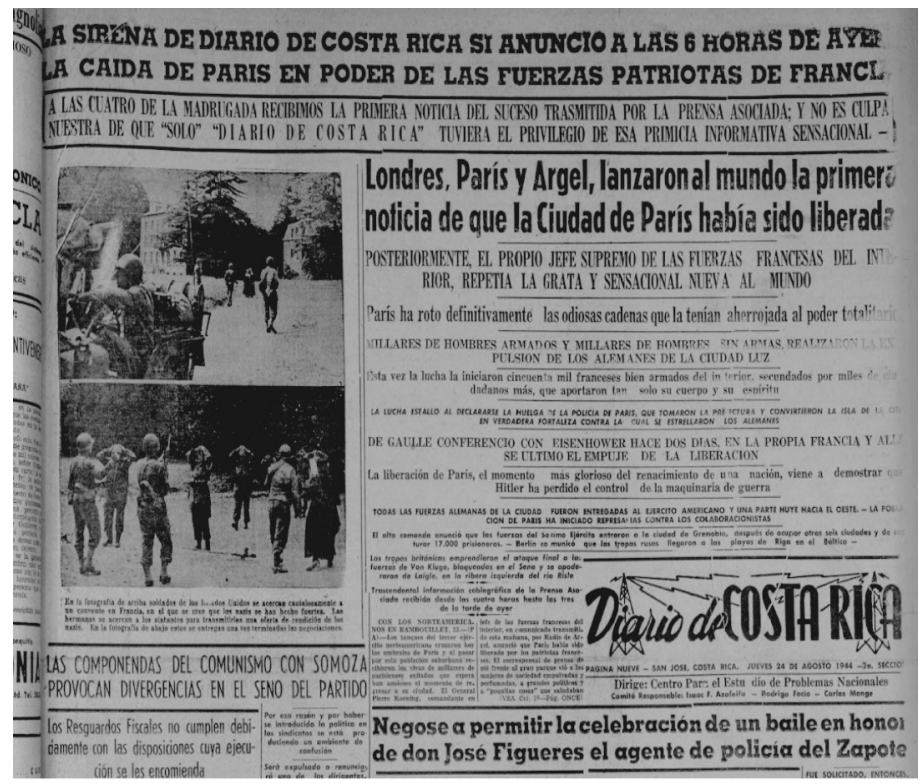

Fuente: Diario de Costa Rica, 25-08-1944, 1.

Al día siguiente, 25 de agosto, abiertamente se enfrenta a sus competidores defendiendo que había sido el primero en divulgar la información:

"Diario de Costa Rica", a las seis de la mañana de ayer, toco su sirena al dar al país la noticia de la liberación de París -Doce horas después de haberse burlado de la noticia de la liberación de París, otra empresa periodística, no tubo más remedio que sonar su sirena, dándola como cierta. Una vez más la información de la prensa asociada mantiene el primer puesto.

El diario, en su afán por mostrar su capacidad de cobertura inmediata y veraz de las informaciones, indicaba que la Prensa Asociada había enviado cables permanentemente "desde las cuatro horas hasta las tres de la tarde de ayer" (Diario de Costa Rica, 25-08-1944, 1), lo que demostraba la competencia del diario para informar lo que ocurre en el escenario de una guerra que se pelea a miles de kilómetros de distancia (Figura 10).

Ese mismo día el periódico aseveraba que "la rápida ofensiva aliada hacia el Sena" fue la que condujo a la liberación de París. Agregaban que "centenares de aviones aliados están destrozando los restos del ejército de von Kluge que hasta ahora no han podido cruzar el Sena y huir de las tenazas aliadas". Más aún, se argumentaba que: 
El supremo comando aliado, para evitar toda responsabilidad en vista de que los alemanes irrespetaron el acuerdo de armisticio entre los nazis y los Maquis, declaró que París no se considerará liberada en el sentido militar sino cuando las tropas aliadas entren a la ciudad (Diario de Costa Rica, 25-8-1944, 1).

A esto se adjunta la manifestación del presidente estadounidense Roosevelt, que reza textualmente: “La liberación de París originó ayer una declaración escrita del presidente Roosevelt en que congratula al pueblo francés y a los guerreros aliados" (Diario de Costa Rica, 25-08-1944, 1). Lo que no menciona el periódico es el discurso de De Gaulle en el Ayuntamiento el día de la liberación, exaltó que la liberación de París fue obra de los franceses. Nunca mencionó a los estadounidenses ni a los aliados. El texto es el siguiente:

(París! París ultrajado! París arrasado! París martirizado! Pero París liberado! Liberado por él mismo, liberado por su pueblo, con el concurso de los ejércitos de Francia, con el apoyo y el concurso de toda Francia, es decir, de la Francia combatiente, es decir, de la sola Francia, de la verdadera Francia, de la Francia eterna).

Discurso del general De Gaulle el 25 de agosto de 1944 en el Hôtel de Ville de París (San Román párr. 60).

Si bien el periódico señala que "esta vez la lucha la iniciaron cincuenta mil franceses bien armados del interior, secundados por miles de ciudadanos más, que aportaron tan solo su cuerpo y su espíritu" cuatro renglones después advierte que "todas las fuerzas alemanas de la ciudad fueron entregadas por el ejército americano y una parte huye el Oeste".

En su afán por destacar la participación aliada en esta tarea, se recurre a fotografías de soldados. En ambas los militares están de espaldas. El pie de foto aclara lo que la imagen no muestra:

En la fotografía de arriba soldados de los Estados Unidos se acercan cautelosamente a un convento de Francia, en el que se cree que los nazis se han hecho fuertes. Las hermanas se acercaron a los atacantes para transmitirles una oferta de rendición de los nazis. En la fotografía de abajo estos se entregan una vez terminadas las negociaciones (Diario de Costa Rica, 25-8-1944, 1).

No solo con las fotografías se exalta la participación de los aliados, dejando en el mutismo a los franceses. De hecho, la contribución francesa no se menciona.

La liberación de París, a pesar del valor simbólico como ciudad luz del continente europeo, en todo caso, no significó el fin de la guerra. Habría que esperar más de 12 meses para que las abdicaciones y la firma de la paz se hicieran efectivas. 


\section{Muerte de Benito Mussolini el 30 de abril de 1945}

Un hecho decisivo en la guerra fue la captura el 28 de abril de 1945 y el asesinato por los partisanos italianos de Benito Mussolini dos días después. El periódico costarricense omitió toda información al respecto.

Con la muerte del líder italiano, la suerte de Italia en la guerra estaba echada.

El 1 de mayo, con una llamada en la primera página, los responsables del diario envían la nota sobre la muerte del il Duce a la página 3 en una columna poco visible.

Hitler se suicida el mismo día en que Mussolini es asesinado y el diario publica en primera página un párrafo poco destacado, que dice: “Uno de los funcionarios nazis capturados declaró al comando ruso que Hitler, Goebbels y el jefe de estado mayor Gral Krebs, se suicidaron" (Diario de Costa Rica, 03-05-45, 1) y no hay más.

\section{Capitulación de Alemania el 8 de mayo de 1945}

La capitulación de Alemania mereció un despliegue periodístico que ocupó la totalidad de la primera página del diario del día 8 de mayo de 1945 (Figura 11), como ocurrió con el inicio de la contienda. De igual manera, el fin del conflicto valió el sonido de la sirena para llamar a la población a celebrar el triunfo.

Pero, lo que más se destacó fue la capacidad informativa del diario y de la agencia noticiosa PA, que le vendía las informaciones al periódico. De hecho, como se observa en la Figura 11, tras un conciso y periodísticamente destacable titular de 5 palabras, "Hoy, día de la victoria", enfatiza que el triunfo más que militar fue informativo, "'LA PRENSA ASOCIADA', en el Más Brillante Triunfo informativo de la Guerra, Anunció Ayer a las 9, 30 a.m. la Total Capitulación de ALEMANIA". 


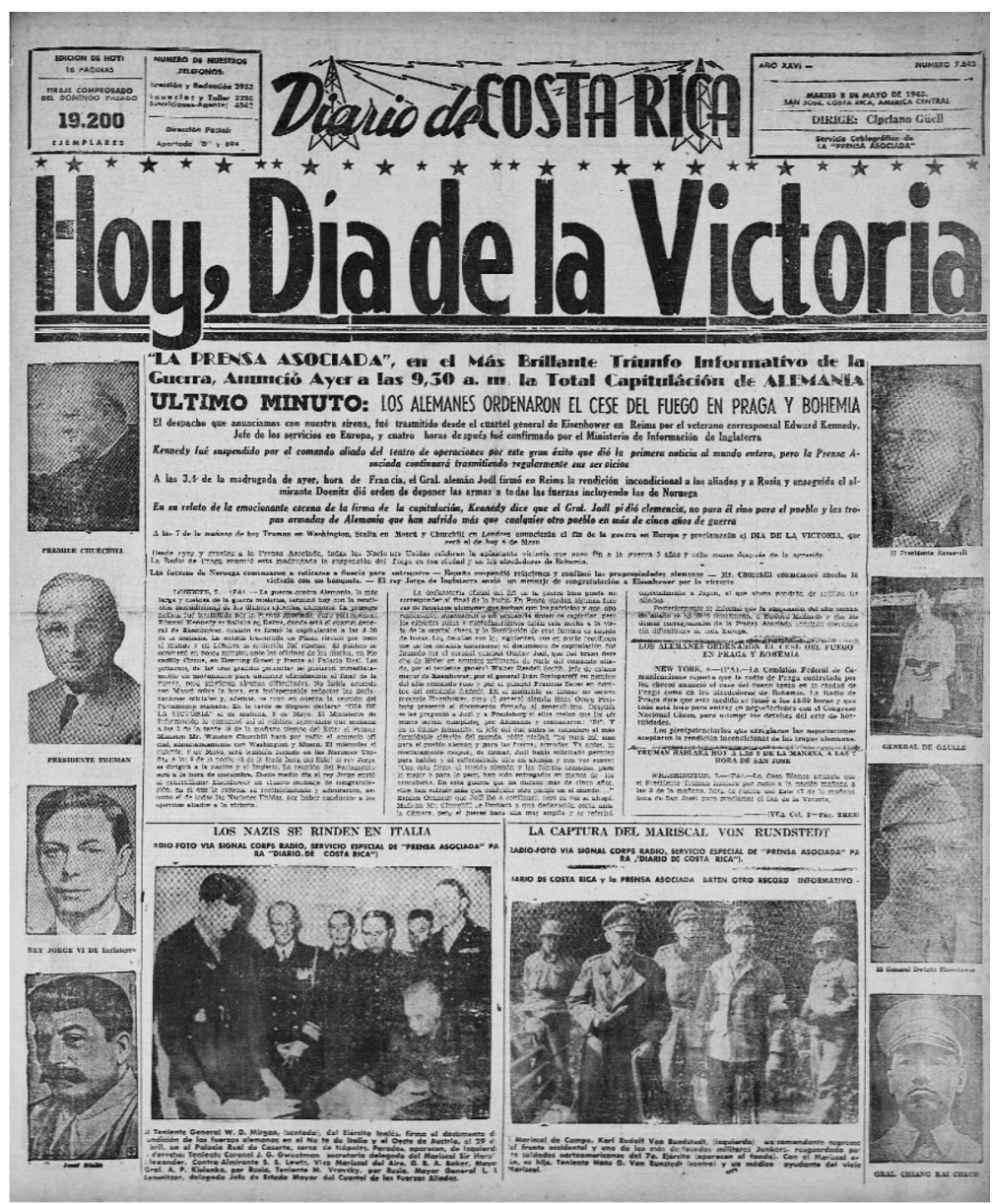

Fuente: Diario de Costa Rica, 8-05-1945, 1.

Las especulaciones periodísticas sobre la rendición de Alemania eran frecuentes desde el mes de abril de 1945 y aun antes. El 30 de ese mes, Hitler se suicidó en el Bunker dando por hecho el gane de los aliados.

La prensa asociada, desde el 29 de abril, aseguraba que Alemania se había rendido, lo que originó los sendos titulares en el Diario de Costa Rica (Figura 12). En primera plana y con letras en negrita acentuadas se informa que "El Senador Connally anunció ayer tarde la rendición incondicional de Alemania", pero a reglón seguido y con letra pequeña, se advierte que "la noticia del Presidente de la Comisión de Relaciones Exteriores del senado conmovió a los Estados Unidos, 
originó ediciones extra de los diarios y provocó tremenda manifestación de entusiasmo en la Conferencia de las Naciones Unidas. Una hora después, el Presidente Truman declaró que la noticia carecía de fundamento" [Negritas añadidas] (Diario de Costa Rica, 29-04-1945, 1).

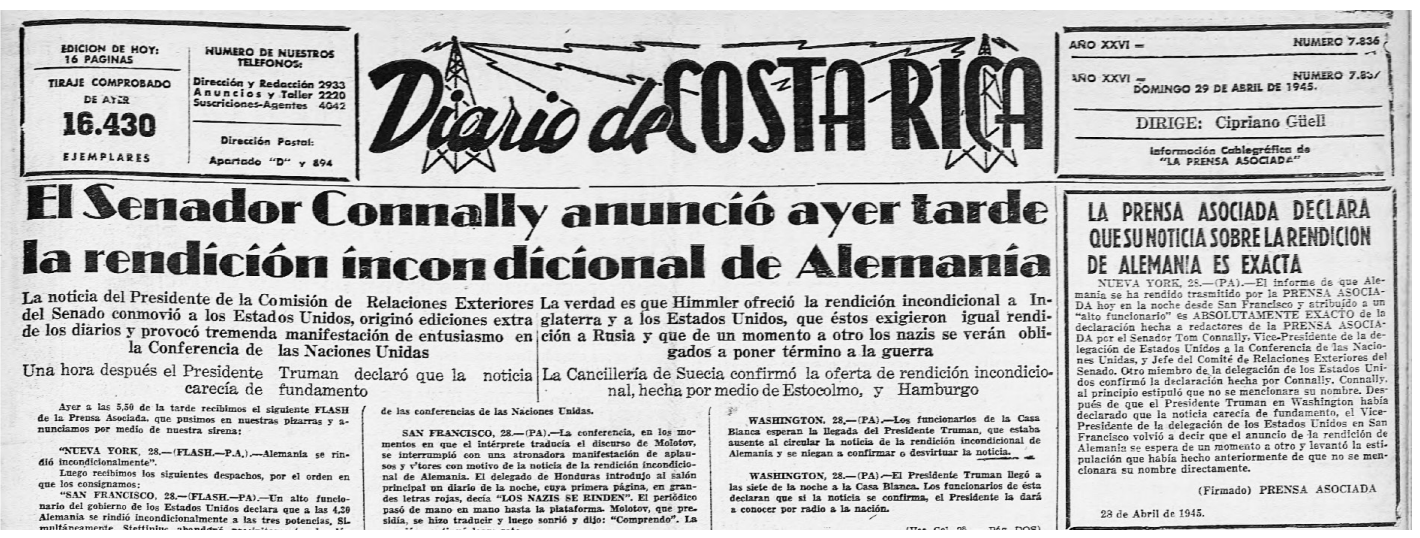

Fuente: Diario de Costa Rica, 29-04-1945, 1.

Con fecha 28 de abril, la PA declara que su noticia sobre la rendición de Alemania es exacta, toda vez que el presidente estadounidense aseveró que la noticia divulgada por la agencia carecía de fundamento.

El despacho de la agencia noticiosa señala que la información que transmitió sobre la rendición alemana se las brindó un alto funcionario estadounidense. "Revelan que la fuente de la información fue el Senador Tom Connally, vicepresidente de la delegación de Estados Unidos a la Conferencia de las Naciones Unidas, y jefe del Comité de Relaciones Exteriores del Senado". Advierten que Connally había pedido que no se nombrara, pero tras las declaraciones del presidente Truman, autorizó mencionar su nombre, pero en esta ocasión dijo "que el anuncio de la rendición de Alemania se espera de un momento a otro", no que ya se había consumado como lo había indicado en la primera entrevista (Diario de Costa Rica, 29-4-1945, 1).

Por su parte, la tecnología permitía entonces la transmisión inmediata de los acontecimientos. El diario insiste en que el anuncio del triunfo aliado fue recibido a través del despacho cablegráfico, emitido desde el cuartel general de Eisenhower y transmitido por el periodista Edward Kennedy. "Por este gran éxito que dio la noticia al mundo" el corresponsal fue suspendido por el alto comando aliado en el escenario de la guerra. 
Exagerando los servicios de la AP, el despacho noticioso asevera que "desde ayer y gracias a la Prensa Asociada, todas las Naciones Unidas celebran la aplastante victoria que puso fin a la guerra 6 años y 8 meses después de la agresión".

Las fotos que ilustran la nota destacan, por primera vez, la referencia de su origen técnico: "Adio-foto via signal corps radio, servicio especial de "prensa asociada" para "Diario de Costa Rica". Agregan que con este despliegue periodístico, el "Diario de Costa Rica y la Prensa Asociada baten otro record informativo".

A pesar del engrandecimiento del papel jugado por la AP, lo cierto es que había demanda de noticias y lo evidencia el hecho de que el tiraje del periódico pasó de 16 000 a 19200 ejemplares ese día.

Dos días antes, se publicó lo que el diario denomina "la primera fotografía de la entrada de los rusos a Berlín”. Con el fin de subrayar la capacidad de la inmediatez del periódico y sus vinculaciones internacionales, exponen la vía a través de la cual obtuvieron esa fotografía:

La agencia rusa "SOY FOTO" en Nueva York, recibió la gráfica, que es de "Estrella Roja", (periódico del ejército soviético) y fue transmitida por radio. Obtenida por servicio especial aéreo de la PRENSA ASOCIADA [y agregaban que] la ofrecemos hoy a nuestros lectores, mostrando el dramático instante en que los tanques hacen su penetración (Diario de Costa Rica, 28-4-1945, 1) (Figura 13).

\section{Primera fotografia de la cutrada de los Rusos a Berlín "Diario de Costa Rica" se anota otro triunfo inforthativo}

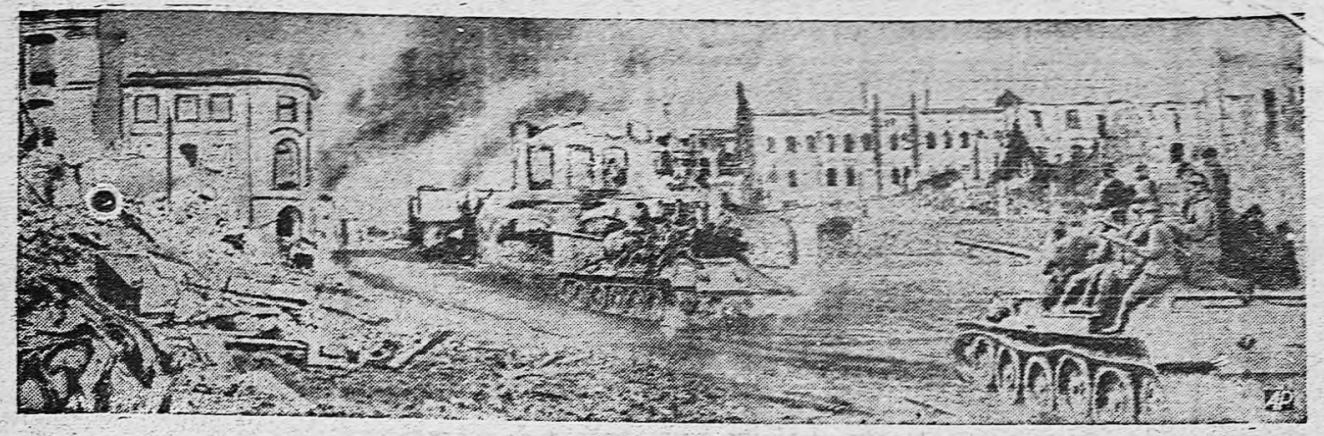

DIARIO DE COSTA RICA tiene el privilegio hoy, -así como suvo en su oportunidad el de dar la noticia de la entrade. de los rusos a Berlín,- de ofrecer la primera fótografía de ese sensational aconfecimiento, que hemos recibido de la dico del fiército Soviético) y fué trasmitida por radio. Obtenida por servicio especial aéreo de la PRENSA ASOCIADA la ofrecemos hoy a nüestros lectores, mostrándo el dramát co instante en que los tanques hacen la penertación.

Fuente: Diario de Costa Rica 28-04-1945, 1. 
Lo que nunca se publicó fue la capacidad de destrucción de los rusos y de la agonía a la que sometieron a la población berlinesa durante meses. La brutalidad alemana durante el conflicto justificaba toda acción en respuesta y represalia, según los medios informativos.

En la primera plana del diario se destacan, a través de fotografías, los principales líderes que representaban a sus países en conflicto.

En los meses siguientes, no hubo un gran despliegue sobre los temas de la guerra. En su lugar, los asuntos domésticos se trataban con más frecuencia.

\section{Bombardeo atómico de las ciudades japonesas de Hiroshima y Nagasaki el 6 y 9 de agosto de 1945}

La destrucción de las ciudades japonesas de Hiroshima y Nagasaki fue una de las masacres más crueles que ha vivido la humanidad. Murieron o quedaron con serias lesiones personas de todas las edades, muchos eran ciudadanos que no estaban involucrados en el conflicto bélico. No obstante, la prensa lo anunció como uno de los principales triunfos de la política del presidente estadounidense Harry Truman.

Hace 16 horas se lanzó la primera "Bomba Atómica" sobre la base japonesa de Hiroshima y cuando se emitió el comunicado de Posdam (sic) ya se contaba con la nueva arma para destruir Japón si rechazaba la última oportunidad que se le dio. [Se trata, según el diario, de la] gran conquista científica que transformará a la humanidad (Diario de Costa Rica, 7-8-1945).

En Potsdam, Alemania, los implicados en el conflicto se reunieron para determinar las condiciones del fin de la guerra. Con el liderazgo de Harry S. Truman presidente de los Estados Unidos, Lósif Stalin, Secretario General del Partido Comunista de la Unión Soviética y el primer ministro de Inglaterra, Winston Churchill, quien será luego sustituido por Clement Attlee, se tomaron las decisiones. Las condiciones para Alemania no resultaron halagüeñas, pero a Japón se le dio en esa conferencia un ultimátum para que se rindiera sin condiciones. Se le exigía a Japón, entre otras cosas, probar de manera convincente que su potencial de guerra estaba destruido (Ultimátum a Japón aprobado en la Conferencia de Potsdam 26 de julio de 1945 párr. 1), se le exigía el establecimiento de un gobierno democrático que instaurara la libertad de palabra, de religión y de pensamiento, así como el respeto a los derechos fundamentales del hombre. Japón rechazó el ultimátum emitido el 26 de julio de 1945 y, como consecuencia, Truman advirtió que "ahora puedes esperar una lluvia de ruina y destrucción como nunca se ha visto en la tierra" (Diario de Costa Rica, 7-8-1945, 1).

La primera noticia sobre la bomba atómica emana del presidente Truman, señalando y alabando los beneficios (sin especificar en qué campos) del descubrimiento y la amenaza que significaba esa bomba para la humanidad, específicamente 
a quienes intentaran tener, desarrollar o mantener un poderío militar (Diario de Costa Rica, 07-08-1945, 1).

El 8 de agosto, el Diario de Costa Rica destacó, como noticia del día, la declaración de los dos pilotos que lanzaron la bomba atómica. Insisten en la luz que produjo la explosión, la que en una masa de polvo y humo, se elevó a 40000 pies "oscureciendo totalmente el área de Hiroshima" (Diario de Costa Rica, 08-08-45, 1).

En el diario del día siguiente, se publica una referencia a la respuesta de Japón donde avisaba que la bomba no solo había destruido vida humana y animal, sino también los aprovisionamientos médicos "no es posible distinguir entre muertos y heridos", subrayaba la nota. Por primera vez se hace referencia a la radioactividad, señalando que "el departamento de Guerra desvirtúa la opinión del Dr. Jacobson de que el área atacada mantiene la radioactividad por 70 años y hace imposible la vida" (Diario de Costa Rica, 09-08-1945, 1).

En una pequeña noticia al final, anuncia que la ciudad industrial de Nagasaki también fue devastada por el lanzamiento de otra bomba atómica. No da más detalles.

El día 10 de agosto, se publica una acotación procedente de la Prensa Asociada donde el presidente Truman "pidió al pueblo japonés abandonar las ciudades industriales porque continuará el bombardeo atómico que, no obstante el barbarismo, es el único medio de acortar la guerra y salvar la vida de muchos millares de jóvenes americanos" (Diario de Costa Rica, 10-8-1945, 1). No hay referencia alguna a los demás pobladores del globo.

Con el fin de explicar el funcionamiento de la bomba atómica, considerada el arma más poderosa del mundo, el Diario de Costa Rica publica un dibujo, con las palabras en inglés, que posiblemente llegó vía la Prensa Asociada, única agencia de noticias que proveía de informaciones internacionales al periódico. El esquema constituye un avance en el periodismo nacional que se limitaba a dar explicaciones verbales de los sucesos que consideraban noticias (Figura 14). 


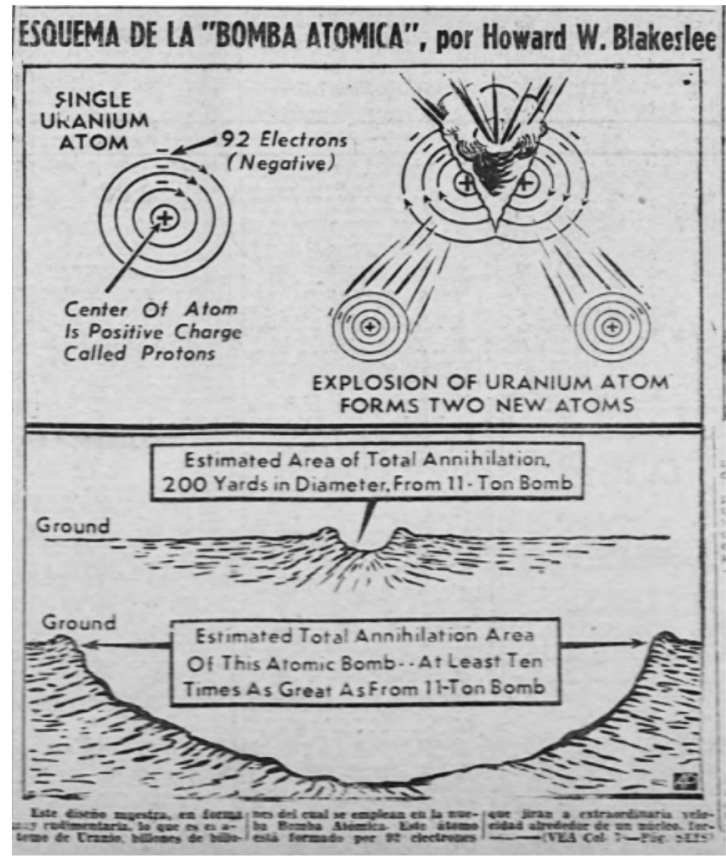

Fuente: Diario de Costa Rica, 11-8-1945, 1.

No será sino hasta una semana después, que se publica una fotografía con detalles del impacto de la bomba atómica. En la Figura 14 se advierte en el pie de grabado lo siguiente: "Densas columnas de humo, a mayor altura de 20000 pies, se elevan sobre Nagasaki, segunda ciudad japonesa que sufrió el impacto de una bomba atómica. Esta foto fue tomada tres minutos después de la terrible explosión" (RADIOFOTO "AP" de gráficas suministradas por las fuerzas Aéreas Estratégicas en Guam).

En una toma aérea, se descubren edificios destrozados y unos cuantos que aún se mantenían en pie. "La destrucción se concentró en un círculo cuyo diámetro es de 19000 pies" (RADIOFOTO "AP" de fotografías tomadas por los camarógrafos de reconocimiento de las fuerzas aéreas norteamericanas) (Figura 15).

Aun no se conocía el impacto y las consecuencias sobre la población y se dependía como fuente, del ejército estadounidense. 


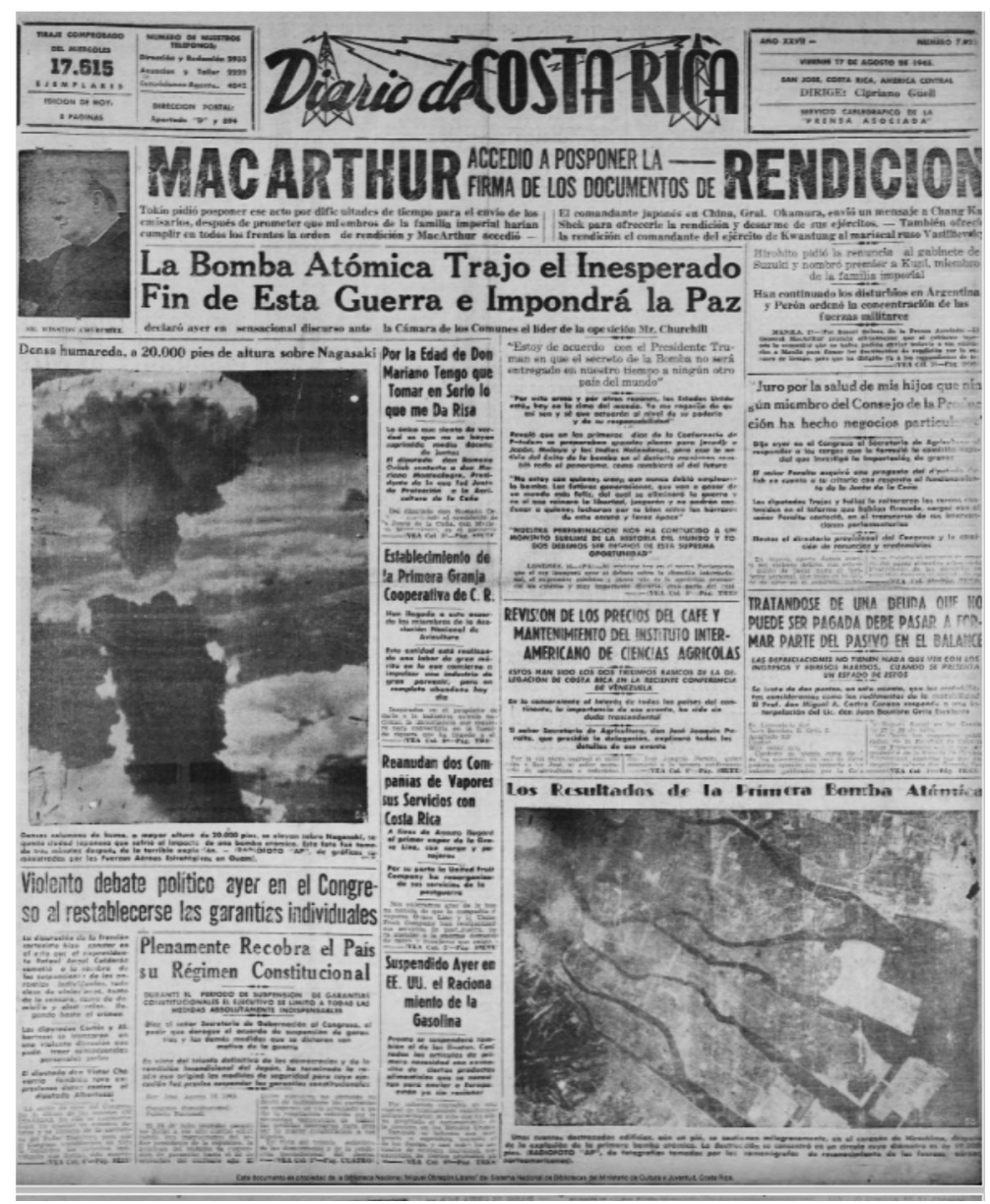

Fuente: Diario de Costa Rica, 17-08-1945, 1.

\section{Conclusión}

La denominada Segunda Guerra Mundial tuvo un impacto radical en el devenir mundial. Cambió la vida en el planeta y sus consecuencias aún se sufren 8 décadas después. No solo cobró millones de vidas inocentes, sino que destruyó buena parte del globo, cuyas secuelas las sobrellevarán aun muchas de las generaciones posteriores a las que vivieron de primera mano la masacre.

La comunicación fue clave en este proceso. El conflicto significó una guerra mediática; por primera vez en la historia de la humanidad las noticias falsas, la propaganda 
y las imágenes influyeron decididamente en el inicio, el desarrollo y el fin de la contienda, tanto en un bando como en el otro. En España, por ejemplo, en octubre de 1944, Alemania desencadena una desafortunada campaña de prensa, que se nutre de mentiras difundidas por la propaganda rusa. Recogiendo noticias falsas de los periódicos moscovitas que anuncian un avance imparable de los aliados en el Mediterráneo, la prensa alemana propaga la noticia de diversos levantamientos comunistas en algunas ciudades españolas, entre ellas Zaragoza, donde -supuestamente-:

Las hordas rojas» habian intentado derrocar el régimen de Franco. Estos infundios sobre la reanudación de la Guerra Civil lesionan gravemente los intereses hispanos de cara al extranjero, causando el consiguiente escándalo. La prensa española apenas recoge los bulos que circulan por Alemania, restándoles importancia (Schulze, 1995, 211).

En particular, Adolfo Hitler aprendió con celeridad los resortes de la oratoria, de la propaganda, de la demagogia, del maniqueísmo y del dominio de las masas (Solar). Desde el comienzo de su ascenso político, creó y divulgó un emblema que lo identificaba: La cruz gamada. "La esvástica se convirtió en el emblema del partido obrero alemán nacionalista, de esa manera unía el misterio del emblema del abad Teodorich von Hagen que viera en su niñez y sus recuerdos con la revista Ostara -racista, anticomunista y esotérica-" (Solar 84).

Desde 1923 Hitler insistió en la urgencia de disponer de un medio de expresión escrito, aunque solo fuera para insultar y calumniar a sus enemigos para denunciar los porcentajes de sangre judía de algunos personajes, lo que les hacía inmediatamente sospechosos de estar vendiendo Alemania a los bolcheviques o al capitalismo francés y anglosajón (Solar). Con Goebels como su mano derecha, un genio de la propaganda, el uso de la mentira fue su modo de operar. Combinó la imposición a través de la violencia con la compra de voluntades y la publicación de periódicos en los que lo menos importante era la verdad. Su fin era la venta de ejemplares. Desde ahí fabricó héroes, compuso himnos, calumnió enemigos políticos, haciendo que se convirtiera en verdad la mentira mil veces repetida, utilizando todos los resortes de la propaganda (Solar).

Los aliados también hicieron lo suyo. Tenían sendas agencias de información, un control estricto sobre lo que se podía o no publicar y, especialmente, un discurso ensayado para los públicos de los periódicos, los medios más importantes para llegar a la población.

La prensa asociada era la empresa noticiosa del mercado periodístico centroamericano y caribe. Funcionando a través de la United Fruit Company, brindaba las informaciones que habían sido filtradas por el gobierno y el ejército estadounidense. El Diario de Costa Rica publicaba lo que contenían los despachos que compraba a la AP. Esta práctica fue también empleada en España. Allí, la agencia de prensa Transocean, alemana, le vendía o cedía informaciones a la Agencia española EFE y "esta las difundía bajo su propia firma" (Schulze, 1995, 201), y eran divulgadas por los periódicos. 
Tal era la confianza en esos despachos que en Nicaragua, por ejemplo, desde mayo de 1940 se prohibió "publicar noticias alarmantes sobre la guerra en Europa (en su defecto) los diarios deberán reducirse a dar las noticias suministradas por las agencias autorizadas imparciales" y una de esas, la única que proporcionaba noticias, era la AP (Diario de Costa Rica, 20-5-1940, 1).

En este contexto se divulgaron los hechos de la guerra. Los principales episodios, por la envergadura y las consecuencias, fueron especialmente filtrados por los bandos en disputa. Los aliados, según el periódico costarricense, siempre tenían victorias, aun en los momentos más difíciles como la caída de Varsovia y de París, que evidentemente perdieron, o los avances sin precedentes de los germanos durante los primeros meses de la guerra.

Es evidente que los comunicados de prensa respondían al binomio información-propaganda repitiéndose lo que durante la Primera Guerra fue común: las campañas de atrocidades, mentiras y difusión de rumores interesados, envueltos en el ropaje de la objetividad. Los objetivos eran los mismos: quebrar la moral del enemigo, dividir y enfrentar a las fuerzas adversarias y lograr la colaboración de los aliados (Bordería, Laguna y Martínez).

Desde el inicio del conflicto bélico, los gobiernos tomaron control de las agencias noticiosas. Havas, por ejemplo, tenía prohibido facilitarles a sus abonados información procedente de Alemania y la AP tampoco podía en tanto tenía que respetar los acuerdos específicos que tenía con las agencias europeas (Schulze, 2004).

Los periodistas eran los que, por su oficio, tenían acceso a información y relación con los altos mandos. No es de extrañar que una buena parte fueron agentes o de uno de los bandos o de ambos a la vez -agentes dobles- (Ruiz).

La tergiversación informativa no fue un fenómeno exclusivo de Costa Rica. En España, por ejemplo, el control de la prensa fue especialmente evidente durante la Segunda Guerra Mundial, “en la que la prensa no solo ocultó información, sino que incluso llegó a distorsionar la realidad difundiendo datos falsos" (Díaz Benites 1047). En Argentina:

Hacia el final de la guerra, los diarios dejaron al lector... un legado de confusión y desconocimiento, ya que pasaron a hablar de un "horror nazi" abstracto. La cobertura de la victoria aliada contribuyó a la consolidación de un paradigma dicotómico en el que el nazismo era la "barbarie" absoluta de la que el mundo se había salvado, y la identidad de sus víctimas pasó a segundo plano (Chinsky 121).

En momentos tan álgidos, pretender objetividad e imparcialidad era una utopía. Los medios vendían la información. Sin duda en ese momento, dadas las circunstancias, las demandas de noticias eran copiosas, pero también era el momento de definir el destino del mundo y cada bando hacía esfuerzos por forjarlo según sus intereses. 


\section{Bibliografía}

Altares, G. Diciembre de 1941: Alemania y Japón pierden la guerra. Recuperado de http://internacional.elpais.com/internacional/2016/12/20/actualidad/1482257258_091336.html

Bordería, E., Laguna, A. y Martínez, F. (Eds.). Historia de la comunicación social. Voces, registros y conciencias. Madrid: Editorial Síntesis, 1998.

Canales, C. y Del Rey, M. La Segunda Guerra Mundial de las trincheras a la guerra total. Madrid: EDAF, 2014.

Chinsky, M. La representación del "horror nazi" en la prensa argentina. Revista de Estudios Sociales, 54, (2015). Recuperado de https://journals.openedition.org/ revestudsoc/9520\#tocto1n3

De memoria. (2 septiembre de 2019). La Segunda Guerra Mundial a través del lente de la prensa mexicana de entonces. Recuperado de https://www.dememoria.mx/internacional/ segunda-guerra-mundial-desde-mexico/

Díaz Benites, J. J. La Segunda Guerra Mundial a través de la prensa Canaria. XV Coloquio de historia canario americana. España: Universidad de las Palmas de Gran Canaria, 2004. Recuperado de https://accedacris.ulpgc.es/bitstream/10553/1696/1/5279.pdf

Lizarazo Cañón, M. (13 de junio de 2017). Grietas del periodismo en la segunda guerra mundial. Colombia: El Espectador.

Peredo Castro, F. M. El periodismo y las agencias noticiosas en México entre 1930 y 1950. México: UNAM, 2015.

Ruiz Doménec, J. E. (Ed.). Historia secreta de la Segunda Guerra Mundial. Barcelona: National Geográfic, 2017.

Sahores, J. La rendición de Francia ante la Alemania de Hitler. Recuperado de http://historiageneral.com/2009/06/26/la-rendicion-de-francia-ante-la-alemania-de-hitler/

San Román, A. 24-25 de agosto de 1944: la liberación de París. Recuperado de http://www.lahaine. org/mundo.php/24-25-de-agosto-de

Schulze, I. Éxitos y fracasos de la propaganda alemana en España (1939-1944). Mélanges de la Casa de Velázquez, 31, 3(1995): 197-217.

Schulze, I. La prensa escrita en los principales países occidentales. Historia del periodismo universal. Barrera, C. (Ed.). Barcelona: Ariel, 2004. 169-228.

Solar, D. El último día de Adolfo Hitler. Madrid: La Esfera de los libros, 2004.

Suárez, L. Exordio. La Segunda Guerra Mundial (1939-1945). Recuperado de http://www.exordio. com/1939-1945/militaris/batallas/hongkong.html

Viana, I. (14 de mayo de 2016). El desembarco de Normandía pudo acabar en desastre. ABC. Recuperado de https://www.abc.es/archivo/20140606/abci-desembarco-normandia-201406052043.html

Patricia Vega Jiménez. Costarricense, Licenciada en Ciencias de la Comunicación Colectiva y Doctora en Historia ambos de la Universidad de Costa Rica. Autora de publicaciones académicas sobre historia de la comunicación social, historia del consumo, mercado laboral, género y comunicación, entre otras. Actualmente es profesora 
jubilada en condición de profesora e investigadora ad honorem de la Escuela de Ciencias de la Comunicación Colectiva y del Centro de Investigación en Comunicación, ambos de la Universidad de Costa Rica. Fue directora de la ECCC, del Programa de Posgrado en Comunicación y del Centro de Investigación en Comunicación y Vicedecana de la Facultad de Ciencias Sociales.

Contacto: patricia.vega@ucr.ac.cr

ORCID: 0000-0001-7038-8301 
